\title{
Caucasus Connections? New Data and Interpretations for Armenian Obsidian in Northern Mesopotamia
}

\author{
Ellery Frahm ${ }^{1,2^{*}}$, Stuart Campbell ${ }^{3}$, and Elizabeth Healey ${ }^{3}$
}

(1) Department of Anthropology, University of Minnesota, Hubert H. Humphrey Center \#395, 301 19th Ave S, Minneapolis, MN 55455, United States

(2) Department of Anthropology, Harvard University, Peabody Museum, 11 Divinity Ave, Cambridge, MA 02138, United States

(3) School of Arts, Languages, and Cultures, University of Manchester, Oxford Road, Manchester, M13 9PL, United Kingdom

* email addresses: frah0010@umn.edu, elleryfrahm@gmail.com

\section{Keywords}

Armenia; Syria; Turkey; Caucasus; Northern Mesopotamia; Late Neolithic; obsidian sourcing; interregional contact; portable XRF (pXRF); electron microprobe analysis (EMPA)

\begin{abstract}
Contact across long distances is evident in the Neolithic of the Near East, whether driven by social networks, exchange links, or movement of individuals or populations. Movement of material, such as obsidian, can elucidate these processes but is often studied within a bounded world that places Mesopotamia at the center. This paper focuses on links that cut across the traditionally imposed boundaries between Northern Mesopotamia and the Caucasus. While Armenia is one of the world's most obsidian-rich landscapes, reports of Armenian obsidians in Northern Mesopotamia are scarce. The confirmation (or lack thereof) of these rare reports has important consequences regarding the movement of people, material, and information out of the Caucasus. As discussed here, all but one report either cannot be corroborated or are demonstrably erroneous. For one archaeological site, data processing methods led to overlaps in the signals for different obsidian sources. For another site, one element used in source identification suffered from unsystematic error. For other sites, data and key details went unpublished at the time. To corroborate past work that had identified Armenian obsidian at Domuztepe, 66 artifacts were newly sourced by electron microprobe analysis and confirmed by portable X-ray fluorescence. This sample was biased toward artifacts potentially from Armenia. Our analyses revealed that 15 artifacts match Pokr Arteni, one of the most used
\end{abstract}


obsidian sources in Armenia. For reasons not yet clear, obsidian was brought to this Late Neolithic settlement over a distance of $670 \mathrm{~km}$ linearly and more than $800 \mathrm{~km}$ on foot. Additionally, there are artifacts from four other sources in the Kura-Araxes basin, lending extra support to movement of materials, if not people, between the Caucasus and Domuztepe. Furthermore, there are similar patterns in the two chemical varieties of Pokr Arteni obsidian at Domuztepe and at a Late Neolithic site in Armenia, Aratashen, potentially reflecting similar processes or behaviors at this source.

\section{Introduction}

It has been argued that identifying materials, resources, or goods moved "between different areas and different societies are the most tangible evidence that an archaeologist can hope for when looking to establish contact between prehistoric peoples" (Glascock, 2002:1). In this regard, the use of chemical analyses to match obsidian artifacts to their volcanic origins is cited as one of the great success stories in archaeological science (e.g., Williams-Thorpe, 1995; Henderson, 2001; see also a recent discussion by Freund, 2013). Over the past five decades, obsidian artifact sourcing has provided rich evidence to better understand intra- and inter-regional mobility, exchange, and social interactions (e.g., Earle and Ericson, 1977; Ericson and Earle, 1982; Shackley, 1998, 2005; Glascock, 2002; Dillian and White, 2009; and the chapters within). However, the scale of long-distance interaction has a distinct character, connecting non-contiguous regions and groups situated within different natural and cultural contexts. Such interactions would not necessarily occur through routine encounters within day-to-day patterns of mobility or social networks, yet they are observable via the medium of material transport. With a resource such as obsidian, especially where there are multiple potential sources, it is particularly striking if utilized sources lie far more geographically distant than closer -- and apparently functionally equivalent -- geological deposits. While it is well established that cultural factors can be as significant as functional and economic ones in resource selection, the occurrence of materials, including obsidian, at great distances from their sources can sometimes lead to dramatic interpretations, including proposed intercontinental economic networks and foraging areas far larger than ethnographically attested.

In the Near East, the interaction and movement of people between regions, especially those on the Mesopotamian periphery (e.g., the Caucasus, the Balkans, the Iranian Plateau), has long been a favored explanatory device for changes in the archaeological record. As observed by Hackenbeck (2008), mobility, including migration en masse, has often lain at the core of narratives involving the spread of agriculture, metallurgy, and other innovations out of the Near East. That is, the Near East has long been conceptualized as a center from which cultural and technological changes radiated. 
Contemporary perspectives tend to be more nuanced, focusing on a wider range of social contacts and networks (e.g., Mesopotamia as a nexus of an exchange network; Butzer, 1997). Nevertheless, Mesopotamia typically retains a centrifugal role (cf. Kohl, 2007). For example, Pitskhelauri (2012) proposes that a massive influx of Mesopotamians during the fifth and fourth millennia BCE were responsible for "explosive" changes in the material culture of the Caucasus.

There are, though, a number of hypothesized influences on Northern Mesopotamia from the Caucasus based on changes in technology, material culture, and language, for which we can give one example of each. First, obsidian blades at Late Neolithic and Early Chalcolithic Armenian sites were made using the same technique (pressure flaking with a lever) as chert blades at Early and Middle Bronze Age sites in Northern Mesopotamia (Chabot and Pelegrin, 2006, 2012; Chabot et al., 2009), and it has been proposed that this technique developed in an obsidian-rich landscape like Armenia before it was spread to a chert-rich landscape like Mesopotamia (Cauvin, 1996; Thomalsky, 2013). This, of course, is not the sole possibility. An alternative is that the technique independently arose in different regions based on a shared technological "know-how" (Frahm, 2014a). Second, the Early Trancaucasian complex (or the Kura-Araxes culture), largely defined by its red and black burnished vessels with incised decorations, first appears in the Caucasus during the middle fourth millennium BCE, spreads into Eastern Anatolia and Northern Mesopotamia, and eventually reaches as far as the Levant. Kohl (2007) suggests "these materials constitute one of the best examples of prehistoric movements of peoples available for the Early Bronze Age" (97), but others have stressed the roles of exchange, emulation, and nomadism rather than the long-distance movement of people or pots (Rothman, 2003; Abay, 2005; Batiuk and Rothman, 2007; Schwartz et al., 2009; Ur, 2010; Batiuk, 2013). Third, based on linguistic arguments, it has been argued that Hurrian-speaking people, who lived in Northern Mesopotamia during the Bronze Age, originated in the Caucasus (e.g., Stein, 1997; Steinkeller, 1998) and were either immigrants or invaders (e.g., Wilhelm, 1989; Steinkeller, 1998). Others refute such proposals (e.g., Benedict, 1960; von Dassow, 2008). Kuhrt (1995) claims that it is most likely "the Hurrians were a cultural-linguistic group always located among the foothills and mountains fringing the northern Mesopotamian and Syrian plains" (288).

In addition, there is long-standing -- but little studied -- evidence of links between Northern Mesopotamia and the Caucasus based on material culture rather than linguistic inferences. This is perhaps most apparent in the geographic distribution of painted ceramics of the "Halaf" tradition. Although conventionally -- and almost unquestioningly -- defined as Northern Mesopotamian, there is repeated evidence for connections reaching far to the north and northwest. Tilki Tepe, located on the eastern shore of Lake Van, is usually identified as a Halaf site based on the ceramics (Korfmann, 
1982). Links much further afield include an apparent Halaf pot at Kültepe in Azerbaijan (Merpert and Munchaev, 1993). A small number of Halaf ceramics are reported from Late Neolithic strata at Aratashen in Armenia (Palumbi et al., 2014). Additional connections during the Late Neolithic are implied by broader parallels in the ceramics and architecture at Armenian sites such as AknashenKhatunarkh (Badalyan et al., 2010) and Masis Blur (Martirosyan-Olshansky, 2015). Munchaev and Amirov (2009) even argue the Halaf tradition in Northern Mesopotamia was shaped by influences from the Caucasus, echoing older arguments that Halaf material culture was culturally intrusive and brought by immigrants from the Anatolian highlands (e.g., Bogoslavskaja, 1972).

While Armenia is one of the world's most obsidian-rich landscapes, reports of Armenian obsidians in Northern Mesopotamia are scarce. Large-scale patterns of obsidian distribution noted by Renfrew and colleagues (Dixon et al., 1968; Renfrew and Dixon, 1976) have been bolstered by subsequent regional syntheses (Fig. 1), whereby obsidian found at Mesopotamian sites principally originated from a few major sources in Central and Eastern Anatolia. Similar work in the Caucasus (Figure 2) implies that obsidians in this region remained local with very few exceptions. Here we consider rare reports of Armenian obsidians identified at Northern Mesopotamian archaeological sites. There are, to our knowledge, four such published reports, each of which reflects chemical analyses conducted during the 1970s to 1990s (Figure 3a):

1. From the Late Chalcolithic strata of Arslantepe, Fornaseri et al. (1975) potentially identified artifacts that match Gutansar, an obsidian source in central Armenia (Figure 3b).

2. Francaviglia and Palmieri (1998) reported Gutansar obsidian among the surface finds from three sites in northeastern Syria: Tell Barri, Tell Halaf, and Tell Brak.

3. Edens (1999) briefly mentions that "a few" Gutansar obsidian artifacts were identified by a Smithsonian researcher in the Late Chalcolithic Hacınebi assemblage.

4. As reported in Healey $(2000,2007)$, obsidian from Arteni, a volcanic complex in western Armenia, was identified among artifacts from Late Neolithic Domuztepe.

These reports date from the Late Neolithic to Late Chalcolithic, perhaps reflecting a wider bias in Mesopotamian obsidian sourcing toward earlier periods. There are also scarce reports of Armenian obsidians in distant locations beyond Northern Mesopotamia. Blackman et al. (1998) note that seven obsidian artifacts from Tal-i Malyan in southern Iran match Gutansar and the Syunik (Fig. 3b) sources in Armenia, and a single piece of obsidian at the Pottery Neolithic site of Horvat Usa in the southern Levant was attributed to the Arteni complex (Delerue, 2007). It has been hypothesized (Badalyan et al., 2004) that three artifacts from Tell el-'Oueili in southern Iraq, analyzed by Gratuze et al. (1993), and assigned to their "Group 6," were Syunik obsidian, but this attribution is far from 
clear (Frahm, 2014b). Biagi et al. (2014) maintain that four bladelets from Neolithic Lysa Gora in Ukraine match the Syunik obsidian sources, more than $1100 \mathrm{~km}$ away, based on published values (Keller et al., 1996). All other Armenian obsidian identifications appear limited to far northeastern Turkey or northwestern Iran (Fig. 2; e.g., Ghorabi et al., 2010; Nadooshan et al., 2013).

Corroboration of Armenian obsidian identifications in Northern Mesopotamia has notable consequences for the movement of materials, information, and even people out of the Caucasus. As discussed here, the attribution of the first three reports above, however, either cannot be confirmed or are erroneous. Full data and details for the Domuztepe artifacts were not entirely published at the time of analysis, although data for one round of analyses are available in a doctoral dissertation (Healey, 2000) and summarized in articles (Healey, 2007; Healey and Campbell, 2009). The paper at hand provides an opportunity to address the identification of Armenian obsidian at Domuztepe in greater detail. First, we present the data for the original set of analyses, and second, we report our results for an additional 66 artifacts using two independent analytical techniques. Thus, our

focus here is showing that "the most tangible evidence that an archaeologist can hope for" (sensu Glascock, 2002) regarding Caucasus-Northern Mesopotamian contact is scarce but exists - perhaps in abundance - at Domuztepe. Obsidian was carried to this Late Neolithic settlement from Pokr Arteni, a distance of $670 \mathrm{~km}$ linearly, more than $800 \mathrm{~km}$ on foot, and more than $1000 \mathrm{~km}$ through the Euphrates river valley. These results highlight that the Caucasus did not simply receive people, materials, and innovations radiating from Mesopotamia during the Neolithic. Instead of a simple core-periphery system, Northern Mesopotamia and the Caucasus had social contacts that involved the movement of material, if not people, in the opposite direction.

\section{2 - Terminology notes}

Before we proceed, the past and present definitions of "Armenian" and "Caucasus" obsidians must be considered, as must older terms for the Gutansar obsidian source.

\section{1 - “Armenian" obsidians}

In the earliest work of Renfrew and colleagues (e.g., Cann and Renfrew, 1964; Renfrew et al., 1966), "Armenian” obsidians included sources in eastern Turkey. Renfrew et al. (1966) separated the Near East into Cappadocian (e.g., Acıgöl, Göllü Dağ) and Armenian (e.g., Nemrut Dağ, Lake Van area, Kars province) obsidian sources. They used this term "with the medieval state of that name in mind" (Renfrew and Dixon, 1976:139). This usage, though, did not last. Later, they referred to the same region as "Eastern Anatolia" (Renfrew et al., 1968), and Renfrew and Dixon (1976) refer to it 
with the lengthy appellation "Van-Azerbaijan-Armenian Soviet Socialist Republic" region (or VAA). Blackman (1984) used a similarly protracted term: the "Eastern Turkish-Armenian Soviet Socialist Republic" region (or ET-ASSR). Here we follow a simpler approach: Armenian obsidian originates from sources within the contemporary borders of the Republic of Armenia.

Researchers who cite the early work from Renfrew and colleagues sometimes reiterate the "Armenian" label despite its anachronistic meaning. When Cessford and Carter (2005:306) discuss the "identification of Armenian obsidian at" Çatalhöyük by Renfrew et al. (1966), that refers to their "Group 1g" obsidian, which was thought to originate near Lake Van and is now known to be Bingöl B obsidian. Similarly, when Smith (2008:20) mentions that "Armenian obsidian reached as far as Bahrain in the Persian Gulf," he, in fact, refers to an artifact of "Group 1e-f" obsidian (Renfrew et al., 1966), which includes the Acıgöl and Kars sources in Turkey. One even encounters rare statements, especially in the secondary literature, that Armenian obsidians reached Egypt (Aston, 1994), Eastern Europe (Elekes, 2001), and other far-flung locations. Except for those sites discussed in the

Introduction, such claims refer to either "Armenian" obsidian sensu Renfrew et al. (1966) or early identifications not based on chemical sourcing methods.

It could be argued that "Armenian" vs. "Eastern Anatolian" obsidian is an arbitrary distinction based principally on a modern political boundary. To an extent, this is true, but such distinctions, including this one, are prevalent in the literature. Obsidian sources in eastern Turkey are usually labeled the "Eastern Anatolian" sources (Coşkunsu, 2007; Carter et al., 2008, 2013; Le Bourdonnec, 2008; Poupeau et al., 2010; Astruc et al., 2011; Carter, 2011; Forster and Grave, 2012). Across the border, obsidian sources are commonly called “Armenian” (e.g., Williams-Thorpe, 1995; Keller et al., 1996; Barge and Chataigner, 2003; Oddone et al., 2000; Cherry et al., 2010). Therefore, such a distinction is already routine in the literature, and in this case, the use of a contemporary political border alleviates the need for convoluted nomenclature. Additionally, this political border strongly affected obsidian studies -- and archaeology in general -- in the Near East until the 1990s (after the end of the Cold War), as discussed by various authors (e.g., Dixon, 1976; Blackman, 1984; Keller et al., 1996). That legacy continues to shape how obsidian distribution is conceptualized in the Near East. Lastly, the distinction reflects reconstructions of obsidian distribution (Figures 1-2), in which these regions seem to exhibit well defined "supply" (Dixon et al., 1968), "interaction" (Renfrew and Dixon, 1976), or "diffusion" zones (Chataigner et al., 1998).

\section{2 - "Caucasus" obsidians}

It is also worthwhile to propose and utilize a term that reflects the regional geography and 
ecology. One possibility, suitable for our purposes here, is the use of "Caucasus" to denote obsidian sources that occur within both the Kura-Araxes basin and the Caucasus ecoregion, as defined by the World Wildlife Fund-Caucasus (Fig. 3a). Thus, Armenian obsidian sources are a subset of Caucasus sources, and here we discuss sources with the greatest specificity possible (i.e., "Armenian" is more specific than "Caucasus" if the source lies within the Republic of Armenia).

Using this definition, obsidian sources that others have occasionally termed "Northeastern Anatolian" (Chataigner et al., 1998; Poidevin, 1998; Bressy et al., 2005), including the Kars and the Sarıkamış sources, would instead be classified as Caucasus sources here. There are scattered (but increasing) reports of Caucasus obsidians -- but not Armenian ones -- across the Near East: Pasinler obsidian at Tell Kurdu in the Levant (Bressy et al., 2005), at Tell 'Atij in the Khabur Basin (Frahm, 2014a), and at Kenan Tepe in the Tigris Valley (Frahm, forthcoming); Sarıkamış obsidian at Tell Kurdu (Bressy et al., 2005), at Tell Hamoukar in the Khabur Basin (Khalid and Gratuze, 2010-2011), and at Hagoshrim in the southern Levant (Schechter et al., 2013); and other forthcoming reports. Obsidians from these sources are not our principal focus here; however, they have direct relevance as supporting evidence in the identification of Armenian obsidians.

\section{3 - "Erevan" and "Sevan" obsidians}

Even in the 1990s, most studies included only secondhand Armenian obsidians specimens with vague origins, if any at all. Two of the most common Armenian obsidian attributions found in the literature are "Erevan" (e.g., Gratuze et al., 1993; Bader et al., 1994; Francaviglia and Palmieri, 1998) and "Sevan" (e.g., Hall and Shackley, 1994; Gratuze et al., 1993). A map included in WilliamsThorpe (1995) illustrates the state of (Western) knowledge at the time. She placed one star near the capital city, Yerevan, for the "Erevan" obsidian source and a second star near the northwestern tip of Lake Sevan for the "Sevan" source (Fig. 3b). These locations are based on descriptions in the literature (e.g., "a source between the city of [H]razdan and the northwestern tip of Lake Sevan" in Blackman, 1984). In reality, both "Erevan" and "Sevan" obsidian originated from Gutansar, which lies roughly halfway between Yerevan and Lake Sevan (Figure 3b). It was eventually realized that the Lake Sevan source reported by Blackman (1984) was an anthropogenic, not geological, context (i.e., an archaeological site) with artifacts from Gutansar (Blackman et al., 1998).

Renfrew and colleagues acquired their Erevan obsidian specimen from the British Museum (Natural History), now the Natural History Museum in London. Its collector was unknown, but the accession number indicates acquisition in 1942 (Renfrew et al., 1966). We sourced a subsample of "Erevan" obsidian from the Smithsonian Lithological Reference Collection (NMNH \#52092, field 
\#EA 3-5-1). This specimen was part of the obsidian collection of Robert L. Smith, who helped to develop obsidian hydration dating during the 1960s (Friedman and Smith, 1960). The specimen's label reads "USSR, Russian Armenia, Erivan and Deligane (between)." Figure 3b illustrates that Gutansar lies between Yerevan and Dilijan. The Smithsonian's records for NMNH \#117451 (with a different field number: \#EA 3-5-3) include the note: "See Table 1, no. 81 in Renfrew et al. (1966)." That entry is Nemrut Dağ obsidian from the British Museum (Natural History). If a Nemrut Dağ obsidian specimen in Smith's collection originated from the British Museum (Natural History), it is likely that the Erevan specimen did too. Our analyses, as described in Section 8.2, establish that the Smithsonian's “Erevan” obsidian specimen chemically matches Gutansar (Figure 4).

\section{3 - Gutansar obsidian at Arslantepe?}

Fornaseri et al. (1975) report that 17 of 38 sourced artifacts from Arslantepe (Figure 3a) originated from either "Ziyaret" (an earlier term for Meydan Dağ, which some researchers now call the Gürgürbaba Tepe source; Freund et al., 2012) or “Erevan” (Gutansar) based on X-ray intensity ratios, and they proposed that refractive index might resolve this ambiguity. Today, both methods are known to be problematic and prone to source overlaps.

Refractive index was investigated as a technique for sourcing obsidian artifacts long before Renfrew and colleagues showed success using elemental composition (Lucas, 1942, 1947 in Egypt; Boyer and Robinson, 1956 in the American Southwest). Before their use of optical spectrometry for obsidian sourcing, Renfrew and Cann explored the index of refraction, "which turned out to be no use at all" (Renfrew in Bradley, 1993:74). Others have noted similar issues. For example, Cherry (1968) reports that obsidians from Glass Buttes in Oregon had indistinguishable refractive indices, but many different obsidian compositions exist there (Frahm and Feinberg, 2015). Studies in the Caucasus (Nasedkin and Formozov, 1965; Arazova and Mamedov, 1979) established that refractive indices for an obsidian source can vary significantly and that different obsidian sources can have nearly identical indices. One recent effort (Fernández and Leal, 2014) even resulted in overlapping ranges for the six Patagonian obsidian sources involved. Therefore, the refractive investigations of Fornaseri et al. (1975) should be regarded with skepticism, particularly because they characterized sources' refractive indices with so few specimens.

Fornaseri et al. (1975) also utilized wavelength-dispersive X-ray fluorescence (WDXRF) to analyze obsidian specimens and Arslantepe artifacts. With the exception of an unstratified surface find, the obsidian artifacts in question, all flakes, were excavated in the 1960s by the University of Rome. All but one of the sixteen stratified artifacts date to the Late Chalcolithic (4000-3300 BCE). 
The other artifact came from a Late Bronze Age I level (1550-1400 BCE), but it was found in a wall made of Late Chalcolithic and Early Bronze Age materials, meaning that artifacts contained within date to those periods. Seventeen artifacts matched either "Ziyaret" (i.e., Meydan Dağ) or "Erevan" obsidian. The Erevan specimens were collected along the road between Yerevan and Tsakhkadzor (Fig, 3b), $40 \mathrm{~km}$ south of the latter. That places their collection at Gutansar outcrops.

The approach of Fornaseri et al. (1975) yielded the Gutansar-Meydan Dağ overlap (Fig. 5a) despite the fact that quantitative elemental data clearly discern these sources (Fig. 5b). Specifically, Fornaseri and colleagues did not convert the measured X-ray intensities for $\mathrm{Zr}, \mathrm{Y}$, and $\mathrm{Rb}$ into fully quantitative element concentrations. Converting raw intensities into elemental concentrations was a significant undertaking at the time, involving recording a spectrum onto punch cards and using mainframe time to process the data, taking half an hour (or more) per measurement (Nelson et al., 1975). Measuring intensities was faster and less expensive than quantification, and this approach was once common for sourcing (e.g., Brown, 1983; Shackley, 1988). Many of the foundational XRFbased sourcing studies were based on intensity ratios (Jack and Heizer, 1968; Jack and Carmichael, 1969). Using X-ray intensity ratios, though, sources occasionally suffer from overlapping data, such as this Gutansar-Meydan Dağ ambiguity.

To plot measurements on a ternary diagram (Figure 5a), three variables must add up to a constant value (e.g., 100\%). Consequently, Fornaseri et al. (1975) describe their data processing procedures to convert X-ray intensities into ratios:

For each element, five counts are made each lasting 10 seconds, measuring the number of pulses relative to $\mathrm{K} \alpha$ [X-rays] and to the background. The values so obtained for each element, averaged and corrected for the background, are summed, and the sum is normalized to 100 . The percent contribution made by each element is finally calculated... Each point is identified on the basis of the percent contribution of the counts made for zirconium, rubidium, and yttrium. $(236,237)$

They report such an approach is better for non-destructive analysis, and their argument has merit (Hughes, 2010). However, it has been asserted that, by introducing an artificial dependence among elements, X-ray intensity ratios are more prone to ambiguous outcomes due to overlaps between chemically different sources. Shackley (2005:92) explains:

In this method, net intensity counts for three (usually silicic incompatible) elements are selected through XRF, and the intensity data are computed into intrinsic proportions of the three elements through simple data reduction. The resultant data form a ternary system that can be plotted on triangular coordinate graphs... There are two potential problems with 
this method (see Hughes 1984:1-3). First, using only three elements in a ternary system, it is possible that more than one source 'envelope' (the plotted proportional variability of source material) will plot at the same position. The second problem arises when two researchers use differently selected measurements to plot the ternary positions...

[Q]uantitative ( $\mathrm{ppm})$ data frequently plot quite differently than net intensity data.

The first problem here is what occurred with the Gutansar-Meydan Dağ overlap encountered by Fornaseri et al. (1975). The second issue is demonstrated by Figure 3b, and it is why this overlap does not occur for quantitative elemental concentrations.

Fornaseri et al. (1975) noted that a small difference between the Gutansar and Meydan Dağ specimens was statistically significant. On a practical level, however, they concluded that it was not possible to assign the artifacts to one source or the other: "it seems impossible to establish whether their source area is the Erevan area (Armenia) or is instead Ziyaret" (237). Today there is no way to convert the intensity ratios into element concentrations.

Meydan Dağ in Turkey is the most likely origin of the 17 artifacts in question. Its obsidian has been identified at numerous archaeological sites in Mesopotamia and beyond, including Tell Arpachiyah (Forster and Grave, 2012), Tell Aswad (Orange et al., 2013), Tell Brak (Khalidi et al., 2009), Tell Hamoukar (Khalidi et al., 2009), Tell Kurdu (Bressy et al., 2005), and Tell Mozan (Frahm and Feinberg, 2013b). Additionally, Meydan Dağ is thought to be the source of Renfrew's "Group 3a" obsidian (Keller and Seifried, 1990; Chataigner et al., 1998; Bressy et al., 2005). Forster and Grave (2012) also identified Meydan Dağ obsidian at Tell Arpachiyah, where Renfrew et al. (1966) reported Group 3a obsidian, lending additional support to their equivalence. If true, Meydan Dağ obsidian would be known to occur at many other sites throughout the Near East, including Chagar Bazar, Tell Halaf, and Tilki Tepe (Renfrew et al., 1966; Wright, 1969).

\section{4 - Gutansar obsidian at Tell Barri, Tell Brak, and Tell Halaf?}

Francaviglia and Palmieri (1998) analyzed 50 artifacts from four sites in the Khabur Basin: Tell Hamoukar, Tell Barri, Tell Halaf, and Tell Brak (Fig. 3a). Based on XRF analyses in Rome, they reported that one artifact (of seven) from Tell Halaf, one (of five) from Tell Brak, and two (of 22) from Tell Barri were made of "Armenian" or "Erevan" obsidian. The artifacts were all surface finds from stratified tells. They initially describe the origin of the matching specimens as "the district of Erevan, particularly around Lake Sevan" (337), but an addendum to the paper shows the "Armenia" obsidian specimens match those from "Geraber," an alternative transliteration of Jraber, a village near Gutansar (Frahm et al., 2014b). Thus, four artifacts from the three sites are ostensibly made of 
Gutansar obsidian, but two issues indicate this is almost certainly a misattribution.

First, Bingöl B obsidian, one of the most prevalent obsidians at Mesopotamian sites, is not included in their set of geological specimens. Francaviglia and Palmieri (1998) do include another geochemical variety (i.e., peralkaline) obsidian from the Bingöl region (known as Bingöl A), but the calcalkaline Bingöl B obsidian is absent. It is important that their analyses were conducted during the 1980s. The bimodal compositions (peralkaline vs. calcalkaline) of obsidian in the Bingöl region were initially documented by Cauvin et al. (1986), so the existence of Bingöl B obsidian was not widely known at the time. Earlier studies had recognized an unknown calcalkaline obsidian among the artifacts at many sites (e.g., "Group 1g” in Renfrew et al., 1966, 1968), but its origin remained unknown until Cauvin et al. (1986).

Since then, Bingöl B obsidian has been identified at dozens of sites throughout the region: Cafer Höyük (Cauvin et al., 1991), Hassek Höyük (Cauvin et al., 1991; Pernicka, 1992), and Göbekli Tepe (Le Bourdonnec, 2008) within the Upper Euphrates Basin; Dja'de (Pernicka et al., 1997), Tell Halula (Pernicka et al., 1997), Jerf el Ahmar (Abbès et al., 2001, 2003; Bellot-Gurlet and Poupeau, 2006), Cheikh Hassan (Pernicka et al., 1997; Abbès et al., 2001, 2003), Mureybet (Pernicka et al., 1997; Abbès et al., 2001, 2003), and Abu Hureyra (Brown and Carter, 2011) within the Middle Euphrates Basin; Tell Kashkashok (Gratuze et al., 1993), Tell Hamoukar (Khalidi et al., 2009), and Tell Mozan (Frahm and Feinberg, 2013b) in the Khabur Basin; Tell Assouad (Gratuze et al., 1993) in the Balikh Basin; Kenan Tepe (Frahm, forthcoming) and Körtik Tepe (Carter et al., 2013) in the Upper Tigris Basin; Tell Kurdu (Bressy et al., 2005) and Tell Atchana (Frahm, forthcoming) in the Amuq Basin; Tell Abd el-Aziz, Tell Aray, and Tell el-Kerkh (Maeda, 2003) in the El-Rouj Basin; El Kowm, Qdeir, and Umm el Tlel (Gratuze et al., 1993; Orange et al., 2013) in the El Kowm oasis; and Tell Arpachiyah (Forster and Grave, 2012) in Iraq, amongst others. Thus, it is difficult to overstate the importance of Bingöl B obsidian throughout Northern Mesopotamia.

Second, the values for one of the two elements used in their source attributions, Ba, appear erroneous. In calcalkaline obsidians, $\mathrm{Ba}$ is often high because it is not accepted into minerals that form in such magma, which, in turn, increases its concentration in the glassy obsidian. In contrast, peralkaline obsidians, like those from Nemrut Dağ and the Bingöl A sources, have low Ba contents, often less than $50 \mathrm{ppm}$. This is due to feldspars within peralkaline magma, which readily accept $\mathrm{Ba}$ and, in turn, greatly reduce its concentration within the obsidian. Francaviglia and Palmieri (1998), however, report Ba contents of about 400 ppm for Nemrut Dağ and Bingöl A obsidians, far too high for peralkaline obsidians. They also list 280 ppm of Ba for East Göllü Dağ obsidian, but published Ba concentrations for this source are 100-150 ppm (Hancock and Carter, 2010). 
Furthermore, the four artifacts in question are offset from the "Armenia" specimens in their Ba versus Zr scatterplot (Figure 6a). That is, these artifacts fall outside the "envelope" defined by the source specimens. Due to this mismatch, chemically "neighboring" obsidians, including Bingöl B obsidian, must be considered. This should not be interpreted as a statement that, with calibrated analyses, these two obsidian sources could be easily mistaken for the other. Instead, Bingöl B and Gutansar are neighboring sources in "compositional space" for some elements. For example, based on Euclidean distance matrices calculated with $\mathrm{Ba}, \mathrm{Fe}, \mathrm{Ti}, \mathrm{Zn}$, and $\mathrm{Zr}$ data, the second-best match for an artifact of Bingöl B obsidian is usually Gutansar (Frahm, 2012: Table 7). Thus, without Bingöl B in a reference database, Gutansar can sometimes be the next closest match.

A hypothesis that Francaviglia and Palmieri (1998) misattributed Bingöl B obsidian artifacts to Gutansar is bolstered by later sourcing research at Tell Brak. Khalidi et al. (2009) sourced eight Late Chalcolithic obsidian artifacts from Tell Brak: four attributed to either Bingöl A or Nemrut Dağ, three to Bingöl $B$, and one to Meydan Dağ, and there were no unidentified artifacts. Other recent studies of Tell Brak obsidian artifacts (i.e., Forster and Grave, 2012; Khalidi, 2014) yielded no data that contradict this hypothesis: Bingöl B obsidian, not Gutansar, is present.

Testing this hypothesis used an approach detailed by Frahm (2014a): comparing published artifact data to a richer geological reference database based on elements highly correlated between the two datasets. In this case, we used an EMPA-based database that includes 965 Southwest Asian obsidian specimens, as discussed in Section 8 here and elsewhere (Frahm, 2010). The source data published by Francaviglia and Palmieri (1998) allow regression analysis using this EMPA database, revealing which elements are best correlated and, thus, most comparable between the two datasets. Specifically, their data for the Acıgöl and Göllü Dağ source complexes as well as Gutansar obsidian were plotted against EMPA values for the same sources (Fig. 7a). Only obsidians of the calcalkaline variety were included in this comparison because peralkaline obsidians, which have very different compositions, could skew the regression analyses. Five elements -- $\mathrm{Al}, \mathrm{Ti}, \mathrm{Fe}, \mathrm{Ca}$, and $\mathrm{Si}$-- have high correlations between the two datasets (Pearson's $r \geq 0.93$; Fig. 7a). This means that these datasets, after they are intercalibrated, can be highly compatible for these five elements.

As expected, correlation between the datasets is poor for Ba. A poor correlation, however, does not indicate which dataset is spurious, so further comparisons are necessary. Specimens from the reference collection were also analyzed by neutron activation analysis (NAA) at the University of Missouri's Research Reactor (MURR) and at the Institute for Nuclear Chemistry in Mainz and by WDXRF at the University of Wisconsin-Eau Claire's (UWEC) Materials Science Center. As shown in Figure $7 b$, these independent datasets exhibit extremely high correlations with the EMPA data for 
$\mathrm{Ba}(r \geq 0.99)$, and the slopes of their best-fit lines nearly equal the ideal value of 1 . The implication is that the Ba values in Francaviglia and Palmieri (1998) are faulty, suffering from an unsystematic error. Unfortunately, Ba was a key element in their attribution of artifacts to Gutansar.

Intercalibration between datasets is achieved by means of linear regression analysis for the highly correlated elements. The equations for the best-fit lines between two datasets (Fig. 7a) can, element by element, make the values for one dataset compatible with the other (Frahm, 2014a). If the first dataset, for example, is consistently higher than the second dataset by $20 \%$, then increasing the values of the second dataset by $20 \%$ will make them directly compatible. In this case, the linear regression equations were applied to the four artifacts' $\mathrm{Al}, \mathrm{Fe}$, and Ti measurements as a means to calculate values compatible with the EMPA database. Figure $6 \mathrm{~b}$ shows the recalibrated artifact data plotted with Bingöl B as well as several Armenian obsidian sources. As hypothesized, the artifacts in question match Bingöl B, not Gutansar or any other source in Armenia. Supplementary Table A lists (1) the published and recalibrated data for the four artifacts and "Erevan" obsidian specimens from Francaviglia and Palmieri (1998) and (2) the EMPA data for Bingöl B and Gutansar obsidians, further establishing that the artifacts in question instead match the former source.

\section{5 - Gutansar obsidian at Hacınebi?}

The only mention of Gutansar obsidian artifacts at Late Chalcolithic Hacinebi consists of a sentence in Edens' (1999) article regarding the organization of chert prismatic blade production at the site. Obsidian artifacts composed less than 1\% of the assemblage at Hacinebi (roughly 24,000 lithic artifacts). An unspecified number of obsidian artifacts was sent to the Smithsonian Center for Materials Research and Education (now called the Museum Conservation Institute) for NAA at the National Institute of Standards and Technology (NIST). Edens (1999:25) writes:

Almost all the obsidian is an opaque black or translucent black or greenish black; INAA analysis by M.J. Blackman of a small sample indicates that most pieces derive from Bingöl and Van sources, but that a few pieces come from the Göllüdağ source in central Anatolia and the Gutansar source in Armenia.

No further information is available. Inquiries have confirmed that no written report was provided to the excavators and that Edens' (1999) note was second-hand information. There appears to be a reason that the Hacınebi results were not published: at the time, a Smithsonian database was seen as a long-term resource that assuaged the need for traditional publication.

With the proliferation of internet access in the 1990s, there was a push toward centralized databases for obsidian sourcing (e.g., Skinner, 1995; Shackley, 1998; Glascock et al., 1998), and the 
Smithsonian's database gained the most momentum. During this period, analytical data and their associated information were deposited in the Smithsonian's Archaeometric Research Collections and Records (SARCAR) database, which was intended to curate data and make them freely available to researchers online (Beck, 1984; Shackley, 1995). Envisioned as a long-term database, SARCAR encountered various challenges, both administrative and scientific, and it ultimately lost support, as discussed by Blackman and Bishop (2007:333):

SARCAR was to provide a central facility with continuing institutional support for analytical data and accompanying descriptive information to accommodate current and future research utilization of archaeometric data... Not long after SARCAR was established, several administrative changes occurred in [the Smithsonian], with resulting emphasis being given to research activities. Resources were removed from SARCAR in order to develop and carry out new programs of archaeometric research.

It has not been possible to establish the disposition of these data. Given the rate of hardware and software obsolescence over the ensuing decades, hopefully one of the current archaeological data repositories will be able to acquire and curate these and other SARCAR data.

\section{6 - Arteni obsidian at Domuztepe?}

Domuztepe is one of the largest known Late Neolithic settlements in the Near East, covering 20 ha (Fig. 3a; Campbell et al., 1999; Carter et al., 2003). It is not only the largest Halaf site in the Kahramanmaraş Valley but also the largest Halaf site to be excavated. At a time when many sites were small (2-3 ha) and their residents were mobile (Bernbeck, 2008), Domuztepe is a long-lasting settlement with apparently continuous occupation until the middle sixth millennium BCE. A longterm research focus at Domuztepe has been understanding the establishment and maintenance of a large settlement and its social cohesion. The site is best conceptualized as a segmented community rather than an integrated settlement or proto-town (Campbell, 2008). Its diverse material culture attests to utilization of local and regional resources to meet most of its residents' daily needs. More exotic materials are also present, and some, like obsidians, were at least partially worked on-site. Their presence can be used to investigate connections with distant peoples and places. Obsidian is particularly useful in this respect because it can be studied from the point of view of its geological origins and techno-typological traits. Craft production and long-distance exchange are considered important markers of social complexity at Domuztepe that can be otherwise difficult to recognize. Consequently, obsidian sourcing can elucidate these phenomena at this settlement. Given abundant chert resources throughout the region, obsidian is hardly crucial as a material for stone tools, yet 
more than 12,000 obsidian artifacts constitute $\sim 18-20 \%$ of the lithic assemblage in most contexts (occasionally, however, as little as 7\%). All phases of lithic production are present for flaked- and ground-stone obsidian artifacts. Finely polished, thin-walled obsidian vessel fragments have been found, as have thicker, less-finished pieces that may indicate local manufacture, which could have been a way to increase the status of obsidian (Campbell et al., 1999).

Two batches of Domuztepe obsidian artifacts were analyzed by Poidevin at the Laboratoire Magmas et Volcans at Université Blaise Pascal: 35 artifacts in 1999 and 19 in 2002. The data were not published at the time, but his results were summarized by Healey $(2000,2007)$. Both samples were nonrandom and intended to address specific questions. The first set, in particular, was biased toward visually distinctive obsidian to assess their macroscopic classification. Poidevin's analyses followed the same methods found in similar work by the same team (e.g., Poidevin, 1998; Chabot et al., 2001). For the first sample, major elements were determined by ICP-AES, while trace elements were measured by ICP-MS for both samples (Supplementary Table B). Seven of these artifacts, all in the first sample, were attributed by Poidevin to the Arteni volcanic complex in western Armenia (Fig. 8; Section 7). Specifically, the artifacts were identified somewhat ambiguously as originating from "Pokr Arteni or the Aragatz flow" (personal communication). Other artifacts were attributed to seven other obsidian sources: seven artifacts to Pasinler (within the Kura-Araxes basin and the Caucasus ecoregion; Fig. 3a), one to Meydan Dağ, one to Nemrut Dağ, four to Bingöl A, seventeen to Bingöl B, fifteen to East Göllü Dağ, and one to Nenezi Dağ (plus two unidentified sources), indicating that Domuztepe residents obtained obsidian from a wide range of sources.

\section{7 - The Arteni complex and its obsidian sources}

The Arteni volcanic complex consists of two eruptive centers: Mets ("Big") Arteni and Pokr ("Little") Arteni (Figure 8a). Both centers generated high-quality obsidian and extensive perlitic deposits during a series of rhyolitic eruptions between $1.2 \pm 0.1$ and $1.4 \pm 0.2$ Ma (e.g., Karapetian, 1966; Komarov et al., 1972; Wagner and Weiner, 1987; Oddone et al., 2000; Karapetian et al., 2001; Chernyshev et al., 2006). A tally of sourcing work (e.g., Badalyan et al., 2004, 2007, 2010; Cherry et al., 2010; Glauberman et al., 2013; Kandel et al., 2013; Adler et al., 2014; Chataigner and Gratuze, 2014b; Frahm et al., 2014b) suggests Pokr Arteni was one of the most used obsidian sources in Armenia (and, as the source of obsidian used today to manufacture tourist trinkets and objets d'art, it remains so). Badalyan et al. (2004) report, based on a summary of largely unpublished studies, Arteni obsidian constitutes at least half of assemblages at sites up to $60 \mathrm{~km}$ away. Due to its high quality and accessibility, Pokr Arteni obsidian was preferred over Mets Arteni obsidian (a ratio of 
30:1 based on Badalyan et al., 2004; Chataigner and Gratuze, 2014b). Given its abundance at local sites, it is unsurprising that Armenian obsidian in Northern Mesopotamia came from Pokr Arteni. Its appearance can be black, grey, red-brown, nearly transparent, and every combination thereof, and its morphology when extracted is similarly variable (Figures 8b-d).

Two chemically similar but distinct obsidian types occur at Pokr Arteni (Pokr Arteni 1 and 2 in Frahm, 2014b; Arteni 2 and 3 in Chataigner and Gratuze, 2014b). It has been proposed that these similar obsidian compositions exist on one continuum, likely due to chemical evolution of the magma over time (Frahm, 2014b), and that obsidian corresponding to the discontinuity between them could be deeply buried, altered (hydrated), or otherwise inaccessible.

Poidevin's (1998) database of Anatolian and Caucasus obsidians included only analyses by Keller and colleagues (Keller and Seifried, 1990; Keller et al., 1996) using WDXRF at the Universität Freiburg. Keller and colleagues recognized three chemical types of obsidian from Arteni (Table 1): Arteni A (reportedly "from flows on the eastern flank of Pokr Arteni," Keller et al., 1996: 78), Arteni B (reportedly from "pyroclastics at Brusok" to the northeast, Fig. 8a), and Arteni C (reportedly from "the voluminous Aragats flow that extends $8 \mathrm{~km}$ to the west of Mets Arteni"). While Poidevin may have expanded his dataset by 2000 (personal communication), the identification of "Pokr Arteni or the Aragatz flow" implies uncertainty regarding the precise locations of the different compositions. Comparing Poidevin's measurements to the Arteni dataset from Keller and colleagues reveals why the Aragats flow was a possible attribution. Figure 9 plots the obsidian sources that they have in common (i.e., the Arteni sources, East Göllü Dağ, Nenezi Dağ, and Meydan Dağ). Arteni A and B fall together, while the Domuztepe artifacts fall with Arteni C, which, according to Keller et al. (1996), reflects the Aragats flow. Our fieldwork and analyses (Table 1) indicate that the attributions listed by Keller and colleagues are incorrect. Instead, Arteni A and B match Mets Arteni, whereas Arteni C matches Pokr Arteni. Similarly, Badalyan et al. (2004) noted that artifacts which the Freiburg lab assigned to the Aragats flow were attributed to Pokr Arteni by others, and the Arteni complex has, over the years, been plagued by characterization issues (Frahm, 2014b).

\section{8 - Methods and materials}

Sixty-six artifacts, selected from 319 exported obsidian artifacts, were newly sourced using two independent analytical techniques and a reference collection of 965 Southwest Asian obsidian specimens. Most of these Domuztepe obsidian artifacts were excavated between 2005 and 2009 and exported for study shortly thereafter. Artifacts with a "red-brown-black" appearance were prioritized in the exported and analyzed samples because this visual type correlated significantly 
with artifacts that Poidevin attributed to Arteni and Pasinler (Healey, 2007; Healey and Campbell, 2009), although the artifacts' visual classification is not a direct focus here. It should be noted that a larger sample is currently being sourced at the University of Manchester.

The 66 artifacts were chemically compared to 965 obsidian specimens from more than 200 sampling loci in Southwest Asia, including more than 450 specimens from Eastern Anatolia, 280 from Central Anatolia, and 170 from Armenia, Georgia, and Azerbaijan (see Frahm, 2010:257-269). Their nomenclature here reflects the original collectors' notes, field descriptions, and labels rather than others' names (e.g., Chataigner and Gratuze, 2014a,b). At present, this reference collection is one of the largest for Near Eastern obsidian sourcing, but this will eventually change as researchers continue to conduct new fieldwork and assemble new obsidian collections.

These artifacts and geological obsidian specimens were analyzed using electron microprobe analysis (EMPA) at the University of Minnesota. EMPA has been used in obsidian sourcing for more than 30 years (e.g., Merrick and Brown, 1984; Merrick et al., 1994; Weisler and Clague, 1998; Tykot, 1995, 1997; Tykot and Chia, 1997; Rosen et al., 2005; Le Bourdonnec et al., 2005, 2010; Wada, 2009; Sanna et al., 2010; Nash et al., 2011; Brown et al., 2013; Frahm and Feinberg, 2013a, 2013b), and it is the technique of choice for tephrochronologists to characterize volcanic glass shards. The methods and conditions followed those in Frahm (2012). A collection of certified standards (e.g., Smithsonian microbeam standards) were used for calibration. Accuracy and reproducibility were evaluated using reference standards (e.g., Smithsonian VG-568 obsidian), inter-laboratory "roundrobin" specimens, and NAA and EDXRF analyses from MURR for more than one hundred matched specimens (Frahm, 2010, 2012). Small, thin slices (2-5 mm) were taken from artifacts to maximize accuracy. The slices were mounted in epoxy discs, ground, and polished to mirror-like finishes in order to minimize error due to surface irregularities or alteration (e.g., hydration).

The artifacts' sources were identified using three approaches: (1) calculation of Euclidean distances between each artifact and geological specimen followed by nearest-neighbor searches of the matrices (Frahm, 2012), (2) two- and three-element scatterplots, and (3) discriminant function analysis (DFA) with well-measured elements that effectively differentiate sources.

A subset of the artifacts (43 of 66; i.e., those still available for analysis) were subsequently analyzed by portable X-ray fluorescence (pXRF), specifically a Thermo Scientific Niton XL3t GOLDD instrument at the University of Minnesota, as an independent means to corroborate our obsidian source identifications. The use of pXRF in obsidian artifact sourcing is now well attested worldwide (see Frahm, 2014b; Frahm and Feinberg, 2015; and the references within). The instrument that we used has a miniaturized 50-kV, Ag-anode X-ray tube. For the measurement of small specimens and 
artifact subsamples, the operating conditions were $40 \mathrm{kV}$ and $\leq 50 \mu \mathrm{A}$ using the "main" X-ray filter and the small spot $\left(\sim 3-\mathrm{mm}, \sim 7 \mathrm{~mm}^{2}\right)$ collimator. To measure the X-rays emitted from a specimen, the instrument has a 25- $\mathrm{mm}^{2}$ silicon drift detector (SDD) with an energy resolution better than 155 $\mathrm{eV}$ in practice. Each measurement took 60 seconds. The correction scheme to account for various physical phenomena within the specimen (e.g., X-ray absorption and attenuation, secondary X-ray fluorescence, photoelectric emission) followed the fundamental parameters (FP) approach, which, in combination with standards, yields excellent accuracy (Heginbotham et al., 2010). The standards were a series of 24 obsidian specimens from Southwest Asia (i.e., Armenia, Georgia, and Turkey), all analyzed by NAA and XRF at MURR and EMPA at the University of Minnesota. Based on the success of pXRF-based sourcing of the Domuztepe artifacts in question, a similar instrument is now used in the new program of obsidian artifact sourcing at the University of Manchester.

\section{9 - New Domuztepe sourcing results}

The newly sourced Domuztepe artifacts can be attributed to ten sources. Fifteen of the 66 artifacts match Pokr Arteni in Armenia. Figure 10a uses a scatterplot of $\mathrm{Ti}, \mathrm{Ba}$, and $\mathrm{Zr}$ to show that one of the artifacts matches the "Pokr Arteni 1" cluster while fourteen match the "Pokr Arteni 2" cluster. Figure 10b shows the same outcome with DFA based on six elements: Ti, Ba, and Zr plus Al, $\mathrm{Fe}$, and $\mathrm{Mn}$ (these elements were chosen because, as variables, they yielded the best discriminating power; see Fig. 10b caption). The Euclidean distance calculations based on seven elements: Ti, Al, Fe, Mn, Ca, Zr, and Ba (the selection process for these elements is detailed in Frahm, 2010:366-372, 450-479). The subsequent nearest neighbor searches of the reference collection corroborate the attributions of these artifacts to Pokr Arteni (Supplementary Table C). Our pXRF data also confirm these obsidian source identifications (Figure 11). These four trace elements -- $\mathrm{Nb}, \mathrm{Sr}, \mathrm{Rb}$, and $\mathrm{Zr}$-are very well measured using pXRF, exhibiting the greatest repeatability and reproducibility (e.g., Grave et al., 2011; Frahm and Feinberg, 2015). The EMPA and pXRF values used to produce these scatterplots are available in Table 2 and Supplementary Table D, respectively.

Figure 12 shows that, as defined in Section 2.2, there are five artifacts from other Caucasus sources. Two artifacts match Sarıkamış, two match two Kars-Arpaçay sources (perhaps equivalent to the "Akhurian River 1 and 2" secondary obsidian deposits in Chataigner and Gratuze, 2014a), and one matches Pasinler (Figure 3a). Their occurrence at Domuztepe lends support to the movement of materials and, perhaps, people between Armenia and this Late Neolithic settlement. It is worth stressing that none of these obsidians were identified at sites previously reported to have Gutansar obsidian. Other sources identified among the Domuztepe artifacts include Göllü Dağ, Bingöl A and 
B, Meydan Dağ, two Nemrut Dağ flows, and, tentatively at least, Muş (38.93 N, $41.25^{\circ}$ E; Figure 3a). The ongoing program of pXRF-based obsidian sourcing at the University of Manchester identified not only additional artifacts from Pokr Arteni but also, very recently, provisionally two artifacts of Gutansar obsidian, further strengthening this tangible connection to Armenia.

Figure 13 shows the artifacts assigned to (a) Pokr Arteni 2, (b) Pokr Arteni 1, (c) Sarıkamış, (d) Kars-Arpaçay 1, (e) Kars-Arpaçay 2, and (f) Pasinler. Based on this set of 66 sourced artifacts, it is not yet possible to answer whether the types of tools and objects made from Pokr Arteni obsidian are significantly different than the items produced from other obsidians. Both blades and flakes are present, some of which have been retouched and/or used. Some of the blades are quite large, and their small platforms and high bulbs suggest they might have been detached using pressure flaking techniques. One sizable flake (Fig. 13a) is from a ground and polished object, and it is attributed to Pokr Arteni 2. Other artifacts of interest include a fragment of a mirror attributed to Kars-Arpaçay 1 (Fig. 13d), and a bead blank and a vessel fragment (Fig. 13c) to Sarıkamış. Supplementary Table E lists the techno-typological, spatiotemporal, and source details for all Domuztepe obsidian artifacts analyzed by Poidevin using LA-ICP-MS and our team by EMPA and pXRF.

\section{0 - Discussion}

Confirmation of Armenian obsidian at Domuztepe is of great interest. For three of the five Northern Mesopotamian sites previously reported to have Gutansar obsidian, the identifications were erroneous, while the other two reports cannot be confirmed, at least at present. Pokr Arenti obsidian, however, has now been corroborated at Domuztepe using two independent techniques, and forthcoming data from ongoing work indicates the presence of more Pokr Arteni obsidian and at least two artifacts made of Gutansar obsidian. What are the implications? Can the abundance of Pokr Arteni obsidian artifacts at Domuztepe be estimated at present? How does the occurrence of Pokr Arteni obsidian at Domuztepe compare to contemporaneous sites in Armenia?

\section{1 - Interpretation and implications}

Maps like those in Figure 1 have long left the impression, as expressed by Williams-Thorpe (1995), that, for the ancient Near East, obsidian "distributions are now established, and it becomes rather less exciting to simply 'fill in the gaps'” (235; see also Frahm, 2014c:180-183). Regarding the dearth of Armenian obsidians in Mesopotamia and other regions, Blackman et al. (1998) proposed that their eventual identification was an inevitability. Specifically, they argued:

The only report positively linking Caucasian sources with obsidian artifacts recovered well 
beyond the Caucasus is from Tal-i Malyan in the highlands of southwestern Iran (Blackman, 1984)... It is likely that comprehensive programs of obsidian analysis from other sites in Mesopotamia and the surrounding highlands to the east will also show an exchange in Caucasian obsidian unknown at this point in time. (222)

As discussed here, though, this largely has not happened. Have Armenian obsidians been hiding in the "gaps" all these decades? According to one recent tally (Frahm, 2010), there are 1600 sourced obsidian artifacts from Mesopotamia and the Levant between the Pre-Pottery Neolithic and the Late Bronze Age, but only 26 of them have been attributed to Armenian sources. Four artifacts from Tell Halaf, Tell Brak, and Tell Barri had erroneous identifications of Armenian (Gutansar) obsidian, seven from Domuztepe and an unknown number from Hacınebi had unpublished data and details, and seventeen from Arslantepe suffered from an overlap with an intensively used obsidian source (Meydan Dağ). It seems then that Armenian obsidians may truly be scarce at sites within Northern Mesopotamia, contrary to the prediction of Blackman et al. (1998). It is also worth noting that, if a truly random sample of Domuztepe obsidian artifacts had been sourced (rather than one that was intentionally biased toward visual diversity of obsidian at the site), Pokr Arteni obsidian might not have been recognized (see Section 10.2). The greater sample sizes enabled by pXRF, together with targeted sampling, might ultimately substantiate Blackman et al. (1998)'s prediction.

\section{2 - Estimating obsidian amounts at Domuztepe}

Research on the Domuztepe obsidian (and chert) assemblage has been a continuing process since excavations started in 1995 (e.g., Healey, 1997, 2000, 2001, 2007, 2011; Campbell et al., 1999; Healey and Campbell, 2009; Campbell and Healey, 2011, 2013). The obsidian assemblage is large $(\sim 12,000$ artifacts), although it only represents a small proportion of the lithic materials used for flaked and ground stone artifacts. Due to the large quantity of obsidian, lab-based chemical analysis was not viable, particularly at the outset of this work in the 1990s. Thus, visual classification was investigated as a means of recognizing and understanding spatiotemporal trends at the site, while acknowledging that visual classes do not perfectly correlate to geological sources. We concur with Carter and Kilikoglou (2007), who cautioned that "visually discriminated source assignations [can] be deeply flawed, albeit with some productive implications" (122). It is perhaps most useful when the profile of the obsidian sources reflected at a given site has been established by chemical means (e.g., Healey, 2007; Healey and Campbell, 2009; Milić et al., 2014). We also emphasize that visual classification has value beyond sourcing endeavors, given that appearance of obsidian was readily perceived by the people who made and used these artifacts on a daily basis (Heyden, 1988; Cauvin, 
1998; Coqueugniot, 1998; Saunders, 2001; Dillian, 2007; Hodgson, 2007).

Based on the results from Poidevin's analyses to test the visual classes (recorded blind) of Domuztepe obsidians, $\sim 75 \%$ of the artifacts were visually attributed to their chemically identified sources with an accuracy $~ 85 \%$ (Healey and Campbell, 2009). Clearly this approach is much less successful than chemical sourcing, but it does offer a link between the deliberately biased sample that has been chemically analyzed and the whole obsidian assemblage. With each artifact observed in transmitted light using a daylight quality bulb for consistency (Healey and Campbell, 2009), five main visual classes were identified - opaque black, grey, green, brown, and red-brown-mahogany -as well as a few artifacts that are completely colorless. Within each visual class, there is variation in translucency (e.g., semi-translucent, cloudy) and inclusions (e.g., stripes, speckles). Proportions of each of the major visual classes are summarized in Table 3, together with the obsidian sources for the artifacts originally analyzed by Poidevin and newly reported here.

Among this sample of artifacts, we note that chemical analyses suggest a strong association between the red-brown-mahogany obsidians (which themselves show several different variations) and Arteni and the Caucasus sources (25 of 27 in Table 3). Of the two exceptions, one is Meydan Dağ obsidian, and the other is Bingöl B. Red-brown-mahogany obsidians can occur at other sources as well, but they have not yet been identified at Domuztepe. If this relationship remains the same throughout the assemblage (and there is no reason to suggest it does not), this might indicate that $\sim 1.5 \%$ of the obsidian assemblage originated from Pokr Arteni and the Caucasian sources $(\sim 130$ artifacts). Within this, we might expect the majority to have come from Pokr Arteni.

We should also note, however, that a significant quantity (11 out of 36) of obsidian artifacts from Pokr Arteni and the Caucasus are not visually distinctive. Pokr Arteni obsidian also occurs at Domuztepe as grey, brown, and colorless artifacts, reflecting the variety of colors observed at the source (Section 7). Calculated at face value, we might expect that more than 600 obsidian artifacts from Pokr Arteni and the Caucasus sources may be present in the Domuztepe assemblage and have colors other than red-brown-mahogany. That, in turn, would suggest that $\lesssim 8 \%$ of the full obsidian assemblage could have originated from sources within the Caucasus. About $2 \%$ of the assemblage may have originated at Pokr Arteni, with nearly half being visually distinctive.

These figures are obviously subject to very large margins of error. However, based on our knowledge of the assemblage at Domuztepe, they do give an indication that Caucasus sources were a small but significant contributor to obsidian at the site, and that Armenia might have contributed more than a token element. Pokr Arteni obsidian is not an isolated occurrence at Domuztepe, and our ongoing program of obsidian sourcing will further refine these numbers. 


\section{3 - Comparison to Late Neolithic Armenian sites}

It is worth considering what is known of obsidian acquisition at Late Neolithic sites closer to the Arteni complex. Significant numbers of artifacts have been sourced from two sites just south of Yerevan (Figure 3b): Aknashen-Khatunarkh (Badalyan et al., 2010) and Aratashen (Badalyan et al., 2004, 2007). Aratashen was the sole Neolithic site studied by Chataigner and Gratuze (2014b), who sourced 30 obsidian artifacts: 15 from Pokr Arteni (50\%), eight from Sarıkamış sources (27\%), five from Gutansar (17\%), and two (6\%) from other sources (i.e., Hatis and Geghasar).

The sample sizes are small, but Domuztepe and Aratashen exhibit similar patterns in use of Pokr Arteni obsidians. The "Arteni 2" and "Arteni 3" clusters in Chataigner and Gratuze (2014b) are equivalent to our "Pokr Arteni 1" and "Pokr Arteni 2" obsidians, respectively (Frahm, 2014b). From Aratashen, Chataigner and Gratuze (2014b) analyzed two artifacts that matched "Arteni 2" obsidian and thirteen that matched "Arteni 3." At Domuztepe, we identified one "Pokr Arteni 1" artifact and fourteen "Pokr Arteni 2" artifacts. This skew toward "Pokr Arteni 2" obsidian does not appear to exist earlier or later, although those sites have even smaller sample sizes (Chataigner and Gratuze, 2014b). However, preliminary findings from the site of Masis Blur, near Aknashen-Khatunarkh and Aratashen, hint that this trend might have a deeper history (Martirosyan-Olshansky, 2015).

At present, the manifestation of these chemical types on the landscape remains unclear, so elucidating the distributions of these obsidians is a priority for future fieldwork. For the moment, this affinity implies that similar processes, either natural (e.g., accessibility at the surface) or social (e.g., exploitation or social control of certain locations), at the Arteni volcanic complex yielded the obsidian at these Late Neolithic settlements.

\section{1 - Concluding remarks}

We report here our attribution of 15 (out of 66) Domuztepe obsidian artifacts to the Pokr Arteni source in Armenia using EMPA and pXRF. Our result corroborates the past identification of Arteni obsidian by Poidevin, the data and details for which were only partially published (Healy, $2000,2007)$. In addition, five artifacts match four other sources in the Caucasus ecoregion and the Kura-Araxes basin: Pasinler ( $n=1$ ), Sarıkamış (2), Kars-Arpaçay 1 (1), and Kars-Arpaçay 2 (1). This sample was nonrandom, so these proportions cannot be simply extrapolated to the full assemblage, but based on imperfect but significant correlations between visual classes to chemically identified sources, we are able to initially suggest that $\$ 8 \%$ of the obsidian assemblage might have originated from these sources. Such diversity implies that the inhabitants of Domuztepe had access to a broad 
network of obsidian distribution during the Halaf period. It is striking that five obsidian sources in the Caucasus ecoregion are reflected among the sourced artifacts (with a sixth recently identified). There is, at present, no other Northern Mesopotamian site with reports of such diverse obsidians from the Caucasus. This includes two sites (Hacınebi and Arslantepe) at which Gutansar obsidian is reported -- but uncorroborated -- as well as three sites where Gutansar obsidian was misidentified. For each of these sites, Gutansar was the only purported Caucasus obsidian source.

At present, Domuztepe is the only known Northern Mesopotamian site with (1) Pokr Arteni obsidian, (2) Armenian obsidian that has been independently confirmed with published data, and (3) obsidian from more than one source within the Caucasus ecoregion and the Kura-Araxes basin (plus obsidians from at least six other sources). Contrary to predictions (Blackman et al., 1998), significant quantities of Armenian obsidians have yet to be identified in Northern Mesopotamia. When exceptions such as Domuztepe are identified, seeking to understand the mechanisms becomes more compelling. It is certain that materials were moved from Armenia and the Caucasus ecoregion to Domuztepe. Is this evidence for some form of mobility, or did the site's inhabitants tap into a network that circulated diverse obsidians? Does the Pokr Arteni obsidian reflect a particular population at this segmented community, or does it reflect long-distance exchange connected to craft production and/or social differentiation? It will require considerably more work in the future to answer such questions with certainty. For now, these results highlight that we cannot merely conceptualize the Caucasus as a periphery that simply received people, materials, and innovations radiating from a Mesopotamian core. Instead, we have tangible evidence of material from Armenia arriving at Domuztepe during the Late Neolithic. Although several previously reported occurrences of Armenian obsidian in Mesopotamia are now less certain, newer - but still rare - studies hint that Domuztepe is not alone as a site with Armenian (e.g., Horvat Usa in the Levant; Delerue, 2007) and Caucasus (e.g., Hagoshrim in the Levant; Schechter et al., 2013) obsidians.

Regarding the connections mentioned in the Introduction, the mechanisms involved likely lie somewhere on a continuum among purely information (i.e., technology, style, language) moving, migrating people retaining information within their population, and autochthonous or evolutionary change without transmission or migration. Identifying the movements of material (or lack thereof) allows us to concentrate on certain portions of that continuum, while acknowledging that exchange of commodities can occur without cultural intermingling and social change. Nevertheless, "obsidian didn't fly" (Binder, 2002:85). Rather than simply "filling in the gaps" (sensu Williams-Torpe, 1995) of earlier studies (Fig. 1-2), insights have been hiding in such gaps for decades, and it is worthwhile identifying and peering directly into them. It is significant if Pokr Arteni obsidian was transported 
to Late Neolithic Domuztepe but, as far as anyone knows, nowhere else in Northern Mesopotamia. If Gutansar obsidian can be confirmed at Arslantepe and/or Hacınebi, it would only be known in the Upper Euphrates basin during the Late Chalcolithic. The roles of long-distance contact and mobility in shaping the ancient Near East have been debated since the nineteenth century and continue to be the focus of intense scholarship (Stein 2001; Marro, 2004, 2012; Abay, 2005; Anthony, 2007; Batiuk and Rothman, 2007; Kohl, 2007, 2009; Özdoğan, 2007; Palumbi, 2008; Paz, 2009; Kozyreva, 2011; Pitskhelauri, 2012; Wilkinson et al., 2012; Pollock, 2013; Potts, 2013; Rothman, 2015; inter alia). The presence or lack of Armenian obsidian at Northern Mesopotamia is one more piece of evidence to elucidate the phenomena that shaped cultural transmission and social change.

\section{Acknowledgments}

The Kahramanmaraş Museum and Turkey's Ministry of Culture and Tourism supported export and testing of the Domuztepe artifacts. Many of the Armenian obsidian specimens were collected by Frahm as part of the Obsidian Resources and Landscapes of Palaeolithic Armenia project, which he co-directs with Boris Gasparyan, Institute of Archaeology and Ethnography, National Academy of Sciences, Armenia and Daniel S. Adler, University of Connecticut. Pavel Avetisyan, Director of the Institute for Archaeology and Ethnography, is greatly thanked for his continuing support of Frahm's work there. Some of the Armenian specimens were also collected by Frahm in collaboration with Khachatur Meliksetian and Sergei G. Karapetian, Institute of Geological Sciences, National Academy of Sciences, Armenia. Suren Kesejyan aided Frahm in sampling at the Arteni complex. Leslie Hale, Smithsonian Institution, arranged for Frahm to analyze obsidian specimens in the collection from M. James Blackman, Robert L. Smith, and James F. Luhr. Michael Glascock at MURR provided NAA and EDXRF data for matched obsidian specimens from the geological reference collection. Phillip Ihinger and Giselle Conde acquired WDXRF data for matched obsidian specimens in the University of Wisconsin-Eau Claire's Materials Science Center. Conde's work on this project was supported, in part, by a Grant for Underrepresented Minority Research from the American Chemical Association. The pXRF instrument used for this study is part of the research infrastructure of the University of Minnesota's Wilford Laboratory of North American Archaeology, directed by Katherine Hayes. Frahm's work was supported, in part, by the University of Sheffield's Department of Archaeology; the NARNIA Project, a Marie Curie training network (Grant \#265010); and by the Department of Earth Sciences, Institute for Rock Magnetism, and Department of Anthropology at the University of Minnesota. Two anonymous reviewers contributed to the clarity of the final paper. 


\section{Table caption}

Table 1. Data for seven Arteni artifacts identified by Poidevin, Arteni geological obsidian specimens from Keller and colleagues (Keller and Seifried, 1990; Keller et al., 1996) in Poidevin (1998), four sets of recent analyses of Mets and Pokr Arteni obsidian specimens in Frahm's collection, and seven specimens analyzed by Chataigner and Gratuze (2014a).

Table 2. EMPA measurements of the Domuztepe artifacts (italicized) and their matching geological specimens. All values are reported in weight percent.

Table 3. Summary of obsidian visual class versus geochemically identified source. Note that 9,357 out of 12,051 obsidian artifacts were examined for appearance.

\section{Figure captions}

Figure 1. Four regional models of Near East obsidian distribution from sources (triangles) in what is now Turkey. Large-scale patterns first observed by Renfrew and colleagues have been reinforced by later regional syntheses, including the conceptualization of Anatolian and Levantine distribution zones supplied by the Central Anatolian obsidian sources (red) and Mesopotamian zones supplied by select Eastern Anatolian obsidian sources (blue).

Figure 2. Zones similar to those in Figure 1 have been proposed for obsidian sources (triangles) in the Caucasus. The focus here is how researchers have conceptualized and defined the distribution of obsidian from Arteni (green) and other sources (blue, yellow, orange, and brown). The result is a map that suggests highly localized distribution of obsidian from the Arteni sources.

Figure 3. (a) Southwest Asian obsidian sources (triangles) and archaeological sites with reported Armenian obsidian (squares), color coded by the ability to confirm or debunk these reports. In this study, "Armenian" obsidian sources are defined by the modern borders of the Republic of Armenia (green), whereas "Caucasus" obsidian sources are defined by the Kura-Araxes basin (cyan) and the Caucasus ecoregion (magenta) as delineated by the World Wildlife Fund. The background map uses National Geophysical Data Center data. (b) Obsidian sources in Armenia (triangles), modern cities mentioned in the text (dots), and the Kura, Araxes, and Hrazdan rivers. The red squares denote the supposed locations of (1) "Erevan" and (2) "Sevan" obsidians as described in the 1990s literature, 
but those locations do not correspond to actual sources.

Figure 4. EMPA analyses of "Erevan" obsidian from the Smithsonian collections demonstrate that it is Gutansar obsidian rather than some other Armenian obsidian.

Figure 5. (a) Redrawn ternary plot from Fornaseri et al. (1975), showing that the normalized X-ray intensity ratios for "Ziyaret" (Meydan Dağ) and "Erevan" (Gutansar) obsidians overlap using such a data handling approach. Identification of the Hotamis Dağ source in the Acıgöl volcanic complex is based on their text description. (b) EMPA data for the same obsidian sources demonstrate that, with quantitative measurements, Meydan Dağ and Gutansar obsidians are readily distinguished.

Figure 6. (a) Redrawn Zr vs. Ba plot from Francaviglia and Palmieri (1998), demonstrating that the Tell Barri, Tell Halaf, and Tell Brak artifacts are not a perfect match to the "Armenian" obsidian and that Bingöl B obsidian (one of the most prevalent obsidians at Mesopotamian sites) is not included among the comparative specimens. (b) When their WDXRF data are recalibrated for compatibility with the EMPA data (Fig. 7 and Supplementary Table A), the artifacts in question match Bingöl B obsidian, not Gutansar or any other Armenian obsidian source, based on their $\mathrm{Fe}, \mathrm{Ti}$, and $\mathrm{Al}$ values.

Figure 7. (a) Several elements have high correlations (Pearson's $r=0.93-0.97$ ) between the WDXRF data of Francaviglia and Palmieri (1998) and the EMPA data for the same obsidians. These best-fit equations can be used to recalibrate their WDXRF data for direct compatibility with the EMPA data. $\mathrm{Ba}$, however, is poorly correlated $(r=0.35)$, suggesting one dataset suffers from unsystematic error. (b) The EMPA values for Ba exhibit very high correlations $(r=0.99-1.00)$ to obsidian measurements from three other analytical laboratories, suggesting that the Ba values of Francaviglia and Palmieri (1998) are erroneous. Unfortunately, Francaviglia and Palmieri (1998) used their Ba data to match artifacts to obsidian sources, including "Armenia” (Figure 6a).

Figure 8. (a) Simplified geological map of the Arteni volcanic complex and (b-d) obsidian deposits associated with Pokr Arteni. It is not clear yet how the different chemical varieties of Pokr Arteni obsidian map onto this landscape. Background images from Google Earth in accordance with their terms of use; geological map based on Karapetian et al. (2001: Fig. 5) as well as field observations; and field photographs by Frahm. 
Figure 9. Three-dimensional scatterplot for the obsidian sources in common between Poidevin's artifact measurements and the geological data of Keller and colleagues (i.e., the Arteni sources, East Göllü Dağ, Nenezi Dağ, and Meydan Dağ). Arteni A and B fall together, and the Domuztepe artifacts fall with Arteni C of Keller and colleagues. These data are summarized in Table 1.

Figure 10. EMPA measurements show that fifteen Domuztepe artifacts match Pokr Arteni. These plots also establish that nine artifacts match East Göllü Dağ, two artifacts match Sarıkamış, and one artifact matches the Kars-Arpaçay 2 obsidian source. These obsidian sources are among those most compositionally similar to Pokr Arteni 1 and 2. (1) A plot of Ti, Ba, and $\mathrm{Zr}$ demonstrates that one artifact matches the "Pokr Arteni 1" cluster and fourteen match the "Pokr Arteni 2" cluster. (b) The same outcome occurs with DFA based on six elements: Ti, Ba, and $\mathrm{Zr}$ plus $\mathrm{Al}, \mathrm{Fe}$, and Mn. The first function (F1) accounts for 55.7\% of the between-group variance, and the second one (F1) accounts for $32.1 \%$, totaling $87.8 \%$ and attesting to high discriminating power of this model. The prior and posterior classifications were identical, exhibiting no erroneous classifications. These functions discriminate the sources very well, as attested by a Wilks' lambda test. The nearer Wilks' lambda is to zero, the more the included variables contribute to discrimination, and a chi-square statistic tests its significance. In this case, Wilks' lambda is 0.000 , and the p-value is $<0.0001$, attesting that these functions well explain group membership.

Figure 11. pXRF measurements confirm that Domuztepe artifacts match Pokr Arteni. The Rb/Nb vs. Sr/Zr plot also illustrates that artifacts also match East Göllü Dağ and Bingöl B obsidian.

Figure 12. EMPA measurements reveal that there are five artifacts from other "Caucasus" obsidian sources (as defined in this paper as occurring within the Caucasus ecoregion and the Kura-Araxes basin; Section 2.2 and Fig. 3a). Their occurrence at Domuztepe lends support to the movement of materials and, perhaps, people between Armenia and this Late Neolithic settlement. (a) A scatterplot of $\mathrm{Ti}, \mathrm{Ba}$, and $\mathrm{Zr}$ establishes that two artifacts match Sarıkamış, two artifacts match two Kars-Arpaçay sources, and one matches Pasinler. (b) The same outcome occurs with DFA based on eight elements: $\mathrm{Ti}, \mathrm{Ba}$, and $\mathrm{Zr}$ as well as $\mathrm{Al}, \mathrm{Ca}, \mathrm{Fe}, \mathrm{K}$, and $\mathrm{Mn}$. The first discriminant function (F1) accounts for $59.8 \%$ of the between-group variance, and the second function (F1) accounts for $27.3 \%$, totaling $87.2 \%$ and attesting to discriminating power of this model. The prior and posterior classifications were identical, exhibiting no erroneous classifications. These functions discriminate the sources very well, as attested by a Wilks' lambda test. The nearer Wilks' lambda is to zero, the 
more the included variables contribute to discrimination, and a chi-square statistic tests its significance. In this case, Wilks' lambda is 0.000 , and the p-value is $<0.0001$, attesting that these functions well explain group membership.

Figure 13. Domuztepe artifacts from Pokr Arteni and other "Caucasus" sources (as defined in this paper as occurring within the Caucasus ecoregion and the Kura-Araxes basin; Section 2.2 and Fig. 3a). (a) Pokr Arteni 2 artifacts. Top row: DT 04 I.3649/50, DT 05 I.4025/1, DT 05 I.3976/1, DT 05 I.3976/2, DT 99 I.2664/1, DT 99 I.2495/10, DT 05 I.4047/1, and DT 05 I.3920/4. Lower row: DT 99 I.2463/2, DT 05 I.3919/2, DT 05 I.4052/1, DT 99 I.2675/2, DT 05 I.3919/1, and DT 05 I.3891/32. (b) Pokr Arteni 1 artifact: DT 09 I.4869/1. (c) Sarıkamış artifacts: DT 08 IX.4292/1 and DT 05 I.4051/1. (d) Kars-Arpaçay 1 artifact: DT 99 I.2512/20. (e) Kars-Arpaçay 2 artifact: DT 05 I.4051/2. (f) Pasinler artifact: DT 05 I.3992/1.

\section{Bibliography}

Abay, E. 2005. The Expansion of Early Transcaucasian Culture: Cultural Interaction or Migration? Altorientalische Forschungen 32(1):115-131.

Abbès, F., Bellot-Gurlet, L., Bressy, C., Cauvin, M.-C., Gratuze, B., Poupeau, G. 2001. Nouvelles recherches sur l'obsidienne de Cheikh Hassan (Vallée de l'Euphrate, Syrie) au Néolithique: PPNA et PPNB Ancien. Syria 78, 5-17.

Abbès, F., Bellot-Gurlet, L., Cauvin, M.-C., Delerue, S., Dubernet, S., Poupeau, G., Stordeur, D. 2003. Provenance of the Jerf el Ahmar (Middle Euphrates Valley, Syria) obsidians. Journal of NonCrystalline Solids 323, 162-166.

Adler, D.S., Wilkinson, K.N., Blockley, S., Mark, D., Pinhasi, R., Schmidt-Magee, B., Nahapetyan, S., Mallol, C., Berna, F., Glauberman, P., Raczynski-Henk, Y., Wales, N., Frahm, E., Jöris, O., MacLeod, A., Smith, V., Cullen, V., Gasparyan, B., 2014. Early Levallois technology and the transition from the Lower to Middle Palaeolithic in the Southern Caucasus. Science 345(6204), 1609-1613.

Akkermans, P.M.M.G., Schwartz, G.M. 2003. The Archaeology of Syria: from Complex HunterGatherers to Early Urban Societies (c. 16,000-300 BC). Cambridge University Press, Cambridge.

Anderson, P., Chabot, J., 2001. Functional analysis of Glossed blades from Northern Mesopotamia in the Early Bronze Age (3000-2500 BC): the case of Tell 'Atij. In: Journees d'etude du Groupe de recherches en archeometrie du CELAT, 1997-1999, pp. 257-276. 
Anthony, D.W. 2007. The Horse, the Wheel, and Language. How Bronze-Age Riders from the Eurasian Steppes Shaped the Modern World. Princeton University Press.

Arazova, R.B., Mamedov, A.I. 1979. Sravnitel'noe izuchenie obsidiana iz eneoliticheskikh poselenii Azerbaidzhana i mestorozhdenii Zakavkaz'ya. Izvestiya AN AzSSr. Seriya istorii, filosofii i prava 3: 50-57.

Arimura, M., Badalyan, R., Gasparyan, B., Chataigner, C. 2010. Current Neolithic Research in Armenia. Neo-Lithics 1/10: 77-85.

Aston, B.G. 1994. Ancient Egyptian Stone Vessels: Materials and Forms. Heidelberger Orientverlag. Astruc, L., Vargiolu, R., Ben Tkaya, M., Balkan-Atlı, N., Özbaşaran, M., Zahouani, H. 2011. Multi-scale tribological analysis of the technique of manufacture of an obsidian bracelet from Assılklı Höyük (Aceramic Neolithic, Central Anatolia). Journal of Archaeological Science 38: 3415-3424.

Badalyan, R., Chataigner, C., Kohl, P. 2004. Trans-Caucasian Obsidian: The Exploitation of the Sources and Their Distribution. In: A View from the Highlands: Archaeological Studies in Honour of Charles Burney, A. Sagona (ed.), pp. 437-465. Ancient Near Eastern Studies.

Badalyan, R., Lombard, P., Avetisyan, P., Chataigner, C., Chabot, J., Vila, E., Hovsepyan, R., Willcox, G., Pessin, H. 2007. New data on the late prehistory of the Southern Caucasus. The excavations at Aratashen (Armenia): preliminary report. In: Lyonnet, B. (Ed.), Les Cultures du Caucase (VIeeIIIe millénaires avant notre ère). Leurs relations avec le Proche-Orient. CNRS éditions, pp. 37-61.

Badalyan, R., Harutyunyan, A., Chataigner, C., Le Mort, F., Chabot, J., Brochier, J.-E., Balasescu, A., Radu, V., Hovsepyan, R. 2010. The Settlement of Aknashen-Khatunarkh, a Neolithic site in the Ararat Plain (Armenia): excavation results 2004e2009. Tüba-Ar 13, 187-220.

Bader, N., Merpert, N.J., Muchaev, R.M. 1994 Les Importations d'Obsidienne sur les Sites des IXeVIIe Millénaires B.P. du Djebel Sinjar. Paléorient 20(2):6-8.

Barge, O., Chataigner, C. 2003. The Procurement of Obsidian: Factors Influencing the Choice of Deposits. Journal of Non-Crystalline Solids 323(1-3):172-179.

Batiuk, S.D. 2013. The fruits of migration: Understanding the 'longue dureé' and the socio-economic relations of the Early Transcaucasian Culture. Journal of Anthropological Archaeology 32:449477.

Batiuk, S., Rothman, M. 2007. Early Transcaucasian Cultures and their Neighbors: Unraveling Migration, Trade, and Assimilation. Expedition 49(1): 7-17. 
Beck, C.W. 1984. Archaeometric Clearinghouse XXI. Journal of Field Archaeology 11(3):341-344.

Bellot-Gurlet, L., Poupeau, G. 2006. Towards a non-destructive multi-step analytical methodology for the provenance determination of archaeological obsidians. Young Chemists' Workshop on Chemistry for the Conservation of Cultural Heritage: Present and Future Perspectives, pp. 1-4.

Benedict, W.C. 1960. Urartians and Hurrians. Journal of the American Oriental Society 80(2):100104.

Bernbeck, R. 2008. Taming time and timing the tamed. In: Córdoba, J., Molist, M., Pérez, .C., Rubio, I., Martínez, S. (eds.). Proceedings of the 5th International Congress on the Archaeology of the Ancient Near East Madrid, April 3-8 2006. Madrid, Centro Superior de Estudios sobre el Oriente Próximo y Egipto III, 709-728.

Biagi, P., Gratuze, B., Kiosak, D.V., Tubolzev, O.V., Popandopulo, Z.H. 2014. The Neolithic obsidians from southeastern Ukraine: first characterization and provenance determination. Anatolia 40: $1-20$.

Binder, D. 2002. Stones making sense: what obsidian could tell about the origins of Central Anatolian Neolithic. In The Neolithic of Central Anatolia, edited by Frédéric Gérard and Laurens Thissen, pp. 79-90. Ege Yayınlarl, Istanbul.

Blackman, M.J. 1984. Provenience studies of Middle Eastern obsidian from sites in highland Iran. In: Archaeological Chemistry III (ed. J. Lambert), pp. 19-50, Advances in Chemistry Series 252, American Chemical Society, Washington, DC.

Blackman, M.J., Bishop, R.L. 2007. The Smithsonian-NIST partnership: the application of instrumental neutron activation analysis to archaeology. Archaeometry 49: 321-341.

Blackman, M.J., Badalian, R., Kikodze, Z., Kohl, P., 1998. Chemical Characterization of Caucasian Obsidian Geological Sources. In: L'obsidienne au Proche et Moyen-Orient: Du Volcan à l'Outil, M.-C. Cauvin, A. Gourgaud, B. Gratuze, N. Arnaud, G. Poupeau, J. L. Poidevin and C. Chataigner (eds.), pp. 205-231. BAR International Series.

Bogoslavskaja, N.F. 1972. On the problem of the origin of the Halaf culture, Sovetskaya Archeologia 2, 3-16.

Boyer, W.W., Robinson, P. 1956. Obsidian artifacts of northwestern New Mexico and their correlation with source material. El Palacio 63: 333-345.

Bradley, R. 1993. An Interview With Colin Renfrew. Current Anthropology 34(1): 71-82. 
Bressy, C., Poupeau, G., Yener, K. 2005. Cultural interactions during the Ubaid and Halaf Periods: Tell Kurdu (Amuq Valley, Turkey) obsidian sourcing. Journal of Archaeological Science 32, 15601565.

Brown, K., Carter, T. 2011. Networking in the Neolithic: Obsidian Sourcing at Abu Hureyra (N. Syria). Presented at Society for American Archaeology 76th Annual Meeting. Sacramento, CA. March 31, 2011.

Brown, F.H., Nash, B.P., Fernandez, D.P., Merrick, H.V., Thomas, R.J. 2013. Geochemical composition of source obsidians from Kenya. Journal of Archaeological Science 40:3233-3251.

Brown, P.E. 1983. Tracing Prehistoric Sources of Obsidian. In Granite Reef: A Study in Desert Archaeology, edited by P. E. Brown and C. L. Stone, pp. 227-241. Arizona State University.

Buccellati, G., Kelly-Buccellati, M. 1988. Mozan 1: The Soundings of the First Two Seasons. Undena Publications.

Butzer, K. 1997. Sociopolitical discontinuity in the Near East c. 2200 BCE: scenarios from Palestine and Egypt. In: Dalfes, H., Kukla, G., Weiss, H. (Eds.), Third Millennium BC Climate Change and Old World Collapse. Springer, Berlin, pp. 245-296.

Campbell, S. 2008. The Dead and the Living in Late Neolithic Mesopotamia. In: G. Bartoloni and M.G. Benedettini (eds.), Sepolti tra i vivi, Buried Among the Living: Evidenza ed interpretazione di contesti funerari in abitato. Atti del Convegno Internazionale, Università degli Studi di Roma "La Sapienza" 26-29 Aprile 2006, pp. 125-140.

Campbell, S., Healey, E. 2011. Stones of the living and bones of the dead? Contextualising the lithics in the Death Pit at Domuztepe. In: E. Healey, S. Campbell and O. Maeda (eds), The State of the Stone: Terminologies, Continuities, and Contexts in Near Eastern Lithics, pp. 327-342. Berlin: Ex Oriente.

Campbell, S., Healey, E. 2013. Obsidian bijouterie, mirrors and vessels in the prehistoric Near East; examples from Domuztepe (Turkey) and Tell Arpachiyah (Iraq). In: O.N. Crandell and V. Cotiugă (eds.), Stories Written in Stone: Programme and Abstracts of the International Symposium on Chert and other Knappable Materials. Iași, Romania, 20-24 August 2013.

Campbell, S., Carter, E., Healey, E., Anderson, S., Kennedy, A. Whitcher, S. 1999. Emerging complexity on the Kahramanmaraş plain, Turkey: the Domuztepe project 1995-1997. American Journal of Archaeology 103:395-418. 
Cann, J.R., Renfrew, C. 1964. The characterization of obsidian and its application to the Mediterranean Region. Proceedings of the Prehistoric Society 30,111-133.

Carter, E., Campbell, S., Gauld, S. 2003. Elusive complexity: new data from late Halaf Domuztepe in South Central Turkey. Paléorient 29(2):117-133.

Carter, T. 2011. A true gift of mother earth: the use and significance of obsidian at Çatalhöyük. Anatolian Studies 61:1-19.

Carter, T., Dubernet, S., King, R., Le Bourdonnec, F.-X., Milić, M., Poupeau, G., Shackley, M.S. 2008. Eastern Anatolian Obsidians at Çatalhöyük and the Reconfiguration of Regional Interaction in the Early Ceramic Neolithic. Antiquity 82, 900-909.

Carter, T., Grant, S., Kartal, M., Coşkun, A., Özkaya, V., 2013. Networks and Neolithisation: sourcing obsidian from Körtik Tepe (SE Anatolia). Journal of Archaeological Science 40:556-569.

Carter, T., Kilikoglou, V. 2007. From Reactor to Royalty? Aegean and Anatolian Obsidians from Quartier Mu, Malia (Crete). Journal of Mediterranean Archaeology 20(1):1-29.

Cauvin, J. 1998 La Signification Symbolique de L'obsidienne. In L'obsidienne au Proche et MoyenOrient: Du Volcan à l'Outil, edited by M.-C. Cauvin, A. Gourgaud, B. Gratuze, N. Arnaud, G. Poupeau, J. L. Poidevin and C. Chataigner, pp. 379-382. BAR International Series.

Cauvin, M.-C., Balkan, N., Besnus, Y., Şaroğlu, F. 1986. Origine de l’Obsidienne de Cafer Höyük (Turquie): Premiers Résultats. Paléorient 12, 89-97.

Cauvin, M.-C., Besnus, Y., Tripier, J., Montigny, R., 1991. Nouvelles analyses d'obsi- diennes du Proche-Orient: modèle de géochimie des magmas utilisé pour la recherche archéologique. Paléorient 17, 5-20.

Cauvin, M.-C., 1996. L'obsidienne dans le Proche-Orient prehistorique: etat des recherches en 1996. Anatolica 22, 1-31.

Cessford, C., Carter, T. 2005. Quantifying the Consumption of Obsidian at Neolithic Çatalhöyük, Turkey. Journal of Field Archaeology 30(3):305-315.

Chabot, J., Poidevin, J.L.,Chataigner, C., Fortin, M. 2001. Caracterisation et Provenance Des Artefacts En Obsidienne de Tell'Atij et de Tell Gudeda (III Millenaire, Syrie). Cahiers d'Acheologie Du CELAT 10: 241-254.

Chabot, J., Eid, P. 2003. Le phénomène des lames cananéennes: état de la question en Mésopotamie du nord et au Levant Sud. In: Le traitement des récoltes: un regard sur la diversité du 
Néolithique au présent. CNRS Éditions, Antibes, pp. 401-415.

Chabot, J., Eid, P., 2007. Stone Tools from a Bronze Age Village (Tell Nusstell, Syria) in Their Wider Context. In: Berytus Archaeological Studies, vol. 50, pp. 7-36.

Chabot, J., Eid, P., 2009. Tell Mozan: le matériel lithique. In: Bianchi, A., Wissing, A. (Eds.), Die Kleinfunde. Studien zur Urbanisierung Nordmesopotamiens. Ausgrabungen 1998-2001 in der zentralen Oberstadt von Tall Mozan/Urkes. Harrassowitz, Wiesbaden, pp. 803-820.

Chabot, J., Pelegrin, J., 2006. Two examples of lithic industries employing pressure flaking with a lever: recent research from Northern Mesopotamia (Syria, Irak) and Southern Caucasus (Armenia). In: UISPP/IUPPS, XV Congress/XV Congrès. Université de Lisbonne. Abstract available online at: http://www.uispp.ipt.pt/ UISPPprogfin/Livro4.pdf.

Chabot, J., Pelegrin, J., 2012. Two examples of pressure blade production with a lever: recent research from the Southern Caucasus (Armenia) and Northern Mesopotamia (Syria, Iraq) (Chapter 6). In: Desrosiers, P. (Ed.), The Emergence of Pressure Blade Making: from Origin to Modern Experimentation. Springer, pp. 181-198.

Chabot, J., Badalyan, R., Chataigner, C. 2009. A Neolithic obsidian industry in the Southern Caucasus region: origins, technology, and traceology. In: Moreau, J.-F., Auger, R., Chabot, J., Herzog, A. (Eds.), Proceedings of the 36th Symposium on Archaeometry, Cahiers d'archéologie du CELAT, 25; Série Archéométrie, 7. CELAT, pp. 151-160.

Chataigner, C., Gratuze, B. 2014a. New Data on the Exploitation of Obsidian in the Southern Caucasus (Armenia, Georgia) and Eastern Turkey, Part 1: Source Characterization. Archaeometry 56: 25-47.

Chataigner, C., Gratuze, B. 2014b. New Data on the Exploitation of Obsidian in the Southern Caucasus (Armenia, Georgia) and Eastern Turkey, Part 2: Obsidian Procurement from the Upper Palaeolithic to the Late Bronze Age. Archaeometry 56: 48-69.

Chataigner, C., Poidevin, J.L., Arnaud, N.O. 1998. Turkish occurrences of obsidian and use by prehistoric peoples in the Near East from 14,000 to 6000 BP. Journal of Volcanology and Geothermal Research 85, 517-537. Chernyshev et al. 2006

Cherry, R.L. 1968. A method of locating petrographic sources of obsidian artifacts. Northwest Anthropological Research Notes 2: 93-98.

Cherry, J.F., Faro, E.Z., Minc, L. 2010. Field survey and geochemical characterization of the southern 
Armenian obsidian sources. J. Field Archaeol. 35 (2), 147-163.

Coqueugniot, É. 1998 L'obsidienne en Méditerranée Orientale aux Époques Post-Néolithiques. In L'Obsidienne au Proche et Moyen Orient: Du Volcan l'Outil, edited by M.-C. Cauvin, A.

Gourgaud, B. Gratauze, N. Arnaud, G. Poupeau, J. L. Poidevin and C. Chataigner, pp. 351-361. British Archaeological Reports. Maison de l'Orient Méditerranéen, Archaeopress, Oxford.

Coşkunsu, G. 2007. Obsidian Assemblage of Mezraa Teleilat: Evidence of Cultural and Chronological Continuation from Late Pre-Pottery Neolithic to Pottery Neolithic. Neo-Lithics 2: 36-43.

Delerue, S. 2007. L'obsidienne dans Le Processus de Néolithisation du Proche-Orient (12000-6500 Aav. J.-C. Cal.). L'universite Michel de Montaigne Bordeaux 3 Spécialité Physique des Archéomateriaux. PhD. thesis .

Dillian, C.D. 2007 Archaeology of Fire and Glass: Cultural Adoption of Glass Mountain in Obsidian. In Under the Shadow: The Cultural Impacts of Volcanic Eruptions, edited by J. Grattan and R. Torrence, pp. 253-273. Left Coast Press, Walnut Creek, California.

Dillian, C.D., White, C.L. 2009. Trade and Exchange: Archaeological Studies from History and Prehistory. Springer Press.

Dixon, J.E., Cann, J., Renfrew, C. 1968. Obsidian and the Origins of Trade. Scientific American 218(3):38-46.

Dixon, J.E. 1976. Obsidian Characterization Studies in the Mediterranean and Near East. In Advances in Obsidian Glass Studies: Archaeological and Geochemical Perspectives, edited by R. E. Taylor. Noyes Press, Park Ridge, New Jersey.

Earle, T.K., Ericson, J.E. 1977. Exchange Systems in Prehistory. Academic Press, New York.

Edens, C. 1999. The Chipped Stone Industry at Hacınebi: Technological Styles and Social Identity. Paléorient 25:23-33.

Elekes, Z. 2001. Ion Beam Based Nuclear Microanalysis of Geological and Archaeological Objects. Doctoral dissertation, University of Debrecen.

Ericson, J.E., Earle, T.K. 1982. Contexts for Prehistoric Exchange. Academic Press, New York.

Fernández, M.V., Leal, P.R. 2014, Determining the provenance of obsidian in southern Patagonia using optical properties. Archaeometry 56, Supplement 1: 1-18. 
Fornaseri, M., Malpieri, L., Palmieri, A.M., Taddeucci, A. 1975. Analyses of Obsidians from the Late Chalcolithic Levels of Arslantepe (Malatya). Paléorient 3(1):231-246.

Forster, N., Grave, P. 2012. Non-destructive PXRF analysis of museum-curated obsidian from the Near East. Journal of Archaeological Science 39: 728-736.

Forster, N., Grave, P., Vickery, N., Kealhofer, L. 2011. Non-destructive analysis using PXRF: methodology and application to archaeological ceramics. X-ray Spectrom. 40:389-398.

Frahm, E. 2010. The Bronze-Age Obsidian Industry at Tell Mozan (Ancient Urkesh), Syria. Ph.D. dissertation, Department of Anthropology, University of Minnesota. Published online through the University of Minnesota's Digital Conservancy: http://purl.umn.edu/99753.

Frahm, E. 2012b. Non-Destructive Sourcing of Bronze-Age Near Eastern Obsidian Artefacts: Redeveloping and Reassessing Electron Microprobe Analysis for Obsidian Sourcing. Archaeometry 54(4):623-642.

Frahm, E. 2014a. Buying Local or Ancient Outsourcing? Locating Production of Prismatic Obsidian Blades in Bronze-Age Northern Mesopotamia. Journal of Archaeological Science 41(1):605-621.

Frahm, E., 2014b. Characterizing obsidian sources with portable XRF: accuracy, reproducibility, and field relationships in a case study from Armenia. J. Archaeol. Sci. 49, 105-125.

Frahm, E., Feinberg, J.M. 2013a. Empires and Resources: Central Anatolian Obsidian at Urkesh (Tell Mozan, Syria) during the Akkadian Period. Journal of Archaeological Science 40(2):1122-1135.

Frahm, E., Feinberg, J.M. 2013b. Environment and Collapse: Eastern Anatolian Obsidians at Urkesh (Tell Mozan, Syria) and the Third-Millennium Mesopotamian Urban Crisis. Journal of Archaeological Science 40, 1866-1878.

Frahm, E., Feinberg, J.M. 2015. Reassessing obsidian field relationships at Glass Buttes, Oregon. J. Archaeol. Sci.: Reports 2, 654-665.

Frahm, E., Feinberg, J.M., Schmidt-Magee, B.A., Wilkinson, K.N., Gasparyan, B., Yeritsyan, B., Karapetian, S., Meliksetian, Kh., Muth, M.J., Adler, D.S. 2014a. Sourcing Geochemically Identical Obsidian: Multiscalar Magnetic Variations in the Gutansar Volcanic Complex and Implications for Palaeolithic Research in Armenia. Journal of Archaeological Science 47:164-178.

Frahm E., Schmidt, B., Gasparyan, B., Yeritsyan, B., Karapetian, S., Meliksetian, Kh., Adler, D.S. 2014b. Ten seconds in the field: rapid Armenian obsidian sourcing with portable XRF to inform excavations and surveys. J. Archaeol. Sci. 41, 333-348. 
Francaviglia, V., Palmieri, A. 1998. Analisi di ossidiane dell'area del Habur (Giazira Settentrionale), in: Pecorella, P.E. (Ed.), Tell Barri/Kahat 2: Relazione Sulle Campagne 1980-1993 a Tell Barri/Kahat, nel Bacino del Habur (Siria). Università degli studi di Firenze, pp. 335-344.

Friedman, I., Smith, R.L. 1960. A New Dating Method Using Obsidian: Part I, The Development of the Method. American Antiquity 25:476-522.

Freund, K.P. 2013. An Assessment of the Current Applications and Future Directions of Obsidian Sourcing Studies in Archaeological Research. Archaeometry 55: 779-793.

Freund, K.P., Carter, T., Contreras, D., Açlan, M., Köse, O. 2012. The character and use of the Gürgürbaba Tepe (Meydan Dağ) obsidian source, (Turkey). Poster at the 17th Annual Meeting of the American Schools of Oriental Research, Chicago, IL.

Ghorabi, S., Nadooshan, F.K., Glascock, M.D., Noubari, A.H., Ghorbani, M. 2010. Provenance of obsidian tools from Northwestern Iran using X-ray fluorescence analysis and neutron activation analysis. IAOS Bulletin 43:14-20.

Glascock, M.D. 2002. Geochemical Evidence for Long-Distance Exchange. Greenwood Publishing.

Glascock, M.D., Braswell, G., Cobean, R.H. 1998. A Systematic approach to obsidian source characterization. In: Shackley, M.S. (Ed.), Archaeological Obsidian Studies: Method and Theory. Society for Archaeological Sciences, pp. 15-65.

Glauberman, P., Gasparyan, B., Wilkinson, K., Frahm, E., Raczynski-Henk, Y., Adler, D.S. 2013. Barozh 12: A New Middle Palaeolithic Open-Air Site on the Edge of the Ararat Plain, Armenia. The Role of the Southern Caucasus on Early Human Evolution and Expansion: Refuge, Hub or Source Area? Tbilisi, Georgia, 15-20 October 2013.

Gratuze, B., Barrandon, J., Al Isa, K., Cauvin, M.-C. 1993. Non-destructive analysis of obsidian artefacts using nuclear techniques: investigation of provenance of Near Eastern artefacts. Archaeometry 35, 11-21.

Hackenbeck, S. 2008. Migration in Archaeology: Are We Nearly There Yet? Archaeological Review from Cambridge 23.2: 9-26.

Hall, M.E., Shackley, M.S. 1994. An Energy Dispersive X-Ray Fluorescence Study of Some Near Eastern Obsidians. Al-Rafidan 15:25-32.

Hancock, R.G.V., Carter, T. 2010. How Reliable are Our Published Archaeometric Analyses? Effects of Analytical Techniques Through Time on the Elemental Analysis of Obsidians. Journal of 
Archaeological Science 37(2):243-250.

Härke, H. 1998. Archaeologists and Migrations: A Problem of Attitude? Current Anthropology 39: $19-46$.

Healey, E. 1997. Domuztepe: Lithics 1997. Neo-Lithics 3/97:10.

Healey, E. 2000. The Role of Obsidian in the Late Halaf. Unpublished Ph.D. dissertation, University of Manchester.

Healey, E. 2001. The role of obsidian at the Halaf site of Domuztepe, S.E. Anatolia. In: Caneva, I. et al. (eds), Beyond Tools: Redefining the PPN Lithic Assemblages of the Levant. Proceedings of the 3rd Workshop on PPN Lithics, Venice, November 1998. Ex Oriente, Berlin, pp. 389-398.

Healey, E. 2007. Obsidian as an indicator of inter-regional contacts and exchange: three case studies from the Halaf period. In: A. Fletcher and A. Greaves (eds), Transanatolia: Bridging the gap between East and West in the Archaeology of Ancient Anatolia, Anatolian Studies 57:171-189.

Healey, E. 2011. Why do people use exotic raw materials? The case of obsidian in the Near East during the Halaf period. In: Saville, A. (ed.), Flint and Stone in the Neolithic Period. Neolithic Studies Group Seminar Papers, Volume 11, pp. 196- 233. Oxbow Books, Oxford.

Healey, E., Campbell, S. 2009. The Challenge of Characterising Large Assemblages of Exotic Materials: a case study of the obsidian from Domuztepe, SE Turkey. Internet Archaeology 26. Heginbotham, A., Bezur, A., Bouchard, M., Davis, J.M., Eremin, K., Frantz, J.H., Glinsman, L., Hayek, L.A., Hook, D., Kantarelou, V., Germanos Karydas, A., Lee, L., Mass, J., Matsen, C., McCarthy, B., McGath, M., Shugar, A., Sirois, J., Smith, D., Speakman, R.J., 2010. An evaluation of interlaboratory reproducibility for quantitative XRF of historic copper alloys. In: Mardikian, P., et al. (Eds.), Metal 2010. Proceedings of the International Conference on Metal Conservation, Charleston, South Carolina, USA, October 11-15, 2010. Clemson University Press, pp. 244-255.

Henderson, J. 2001. The Science and Archaeology of Materials: An Investigation of Inorganic Materials. Routledge.

Heyden, D. 1988 Black Magic: Obsidian in Symbolism and Metaphor. In Smoke and Mist: Mesoamerican Studies in Memory of Thelma D. Sullivan, edited by J. K. Josserand and K. Dakin, pp. 217-236. BAR International Series. Oxford.

Hodgson, S.F. 2007. Obsidian: Sacred Glass from the California Sky. In Myth and Geology, edited by L. Piccardi and W. B. Masse, pp. 295-313. Special Publications. Geological Society, London. 
Hughes, R.E. 1984. Obsidian Studies in the Great Basin. Contributions of the University of California Archaeological Research Facility, vol. 45. University of California.

Hughes, R.E. 2010. Determining the Geologic Provenance of Tiny Obsidian Flakes in Archaeology Using Nondestructive EDXRF. American Laboratory 42:27-31.

Innocenti, F., Mazzuoli, R., Pasquare, G., Radicati di Brozolo, F., Villari, L. 1976. Evolution of the Volcanism in the Area of the Interaction between the Arabian, Anatolian, and Iranian Plates (Lake Van, Eastern Turkey). Journal of Volcanology and Geothermal Research 1:103-112.

Innocenti, F., Mazzuoli, R., Pasquare, G., Serri, G., Villari, L. 1980. Geology of the Volcanic Area North of Lake Van (Turkey). Geologische Rundschau [International Journal of Earth Sciences] 69(1):292-322.

Jack, R.N., Carmichael, I.S.E., 1969. The Chemical “Fingerprinting” of Acid Volcanic Rocks. Short Contributions to California Geology: Special Report. California Division of Mines and Geology, pp. 17-32.

Jack, R.N., Heizer, R.F. 1968. “Finger-printing” of some Mesoamerican obsidian artifacts. In: Contributions of the University of California Archaeological Research Facility, vol. 5, pp. 81-100.

Kandel, A.W., Gasparyan, B., Frahm, E., Taller, A., Weissbrod, L. 2013. Latest Results from Aghitu-3, an Early Upper Paleolithic Cave Site in Armenia. Hugo Obermaier Society for Quaternary Research and Archaeology of the Stone Age Meeting, Vienna, 2-6 April.

Karapetian, S.G., 1966. Eruption centers of Pliocene acid rocks of Armenia (in Russian). Volcanic And Volcano-Plutonic Formation, vol. 2. Nauka, Moscow, pp. 127-133.

Karapetian, S.G., Jrbashian, R., Mnatsakanian, A.Kh., 2001. Late collision rhyolitic volcanism in the north-eastern part of the Armenian Highland. Journal of Volcanology and Geothermal Research 112:189-220.

Keller, J., Djerbashian, R., Pernicka, E., Karapetian, S.G., Nasedkin, V. 1996. Armenian and Caucasian obsidian occurrences as sources for the neolithic trade: Volcanological setting and chemical characteristics. In: Ş. Demirci, A.M. Özer, G.D. Summers (eds.): Archaeometry 94. Proc. of the 29th Int. Symp. on Archaeometry, 9-14 May 1994, Ankara, pp. 69-86.

Keller, J., Seifried, C. 1990. The Present Status of Obsidian Source Identification in Anatolia and the Near East. PACT 25: Volcanology and Archaeology, Proceedings of the European Workshops of Ravello 25:57-87. 
Khalidi, L. 2014. Fifth millennium BC obsidian production in Area TW, Tell Brak. In: Preludes to Urbanism: Studies in the Late Chalcolithic of Mesopotamia in Honour of Joan Oates, ed. by H. Crawford, A. McMahon, and J.N. Postgate, pp. 69-88. Cambridge: McDonald Institute for Archaeological Research.

Khalidi, L., Gratuze, B. 2010-2011. Late Chalcolithic lithic assemblage at Tell Hamoukar's Southern Extension. Berytus 53-54: 15-38.

Khalidi, L., Gratuze, B., Boucetta, S., 2009. Provenance of obsidian excavated from Late Chalcolithic levels at the sites of Tell Hamoukar and Tell Brak, Syria. Archaeometry 51, 879-893.

Kohl, P.L. 2007. The Making of Bronze Age Eurasia. Cambridge University Press.

Kohl, P.L. 2009. Origins, Homelands and Migrations: Situating the Kura-Araxes Early Transcaucasian 'Culture' within the History of Bronze Age Eurasia. Tel Aviv 36:241-265.

Komarov, A.N., Skovorodkin, N.V., Karapetian, S.G. 1972. Determination of the age of natural glasses according to tracks of uranium fission fragments (in Russian). Geochimia (N6):693-698.

Korfman, M. 1982. Tilkitepe: die ersten Ans, tze pr,,historischer Forschung in der östlichen Türkei. Verlag Ernst Wasmuth, Tübingen.

Kozyreva, N.V. 2011. Interaction of ethnic groups in the early history of Mesopotamia. Vestnik drevnej istorii 3:3-29.

Kuhrt, A. 1995. The Ancient Near East c. 3000-330 BC, Volume One. Routledge History of the Ancient World. Routledge, London.

Le Bourdonnec, F.-X., Lugliè, C., Dubernet, S., Bohn, M., Poupeau., G. 2005. Monte Arci (Sardinia) Obsidians: New Geochemical Data from Electron Microprobe and Ion Beam Analysis. In Le vie dell'Ossidiana nel Mediterraneo ed in Europa, pp. 129-14.

Le Bourdonnec, F.-X., Poupeau, G., Luglie, C. 2010. The Monte Arci (Sardinia, Western Mediterranean) Obsidians: Characterization by Multivariate Analysis from SEM-EDS, EMP-WDS and PIXE Elemental Compositions. In L'ossidiana del Monte Arci nel Mediterraneo. Nuovi Apporti Sulla Diffusione, sui Sistemi di Produzione e Sulla Loro Cronologia, Atti del $5^{\circ}$ Convegno Internazionale (Pau, Italia, 27-29 Giugno 2008), pp. 13-28. Le Bourdonnec 2008

Lucas, A. 1942. Obsidian. Annales du Service des Antiquités de l'Egypte 41: 271-275. Lucas, A. 1947. Obsidian. Annales du Service des Antiquités de l'Egypte 47: 113-123. 
Maeda, 0. 2003. Prehistoric Obsidian Distribution in the Rouj Basin. In Archaeology of the Rouj Basin. Volume 1: Regional Study of the Transition from Village to City in Northwest Syria, pp. 167184.

Marro, C. 2004. Upper Mesopotamia and the Caucasus: an essay on the evolution of routes and road networks from the Old Assyrian kingdom to the Ottoman Empire. In: A View from Highlands: Archaeological Studies in Honor of Charles Burney. Anthony Sagona (ed.), pp. 91-120.

Marro, C. 2012. After the Ubaid. Interpreting Change from the Caucasus to Mesopotamia at the Dawn of Civilization (4500-3500 BC). Varia Anatolica, vol. 27. Ege Yayinlari.

Martirosyan-Olshansky, K. 2015. Provenance Study of Obsidian Artifacts from the Neolithic Settlement of Masis Blur (Armenia) Using Portable X-ray Fluorescence Spectrometry. Poster presented at the Annual Meeting of the Society for American Archaeology, San Fransisco, CA.

Merpert, N.I., Munchaev, R.M. 1993. Yarim Tepe II: The Halaf levels. Early Stages in the Evolution of Mesopotamian Civilisation: Soviet Excavations in Northern Iraq. N. Yoffee and J. J. Clark. Tuscon and London, University of Arizona Press: 129-162.

Merrick, H., Brown, F. 1984. Rapid Chemical Characterization of Obsidian Artifacts by Electron Microprobe Analysis. Archaeometry 26(2): 230-236.

Merrick, H., Brown, F., Nash, W. 1994. Use and Movement of Obsidian in the Early and Middle Stone Ages of Kenya and Northern Tanzania. In Society, Culture, and Technology in Africa, edited by S.T. Childs, pp. 29-44. Masca Research Papers in Science and Archaeology.

Milić, M., Brown, K.. Carter, T. 2013. A visual characterisation of the the Çatalhöyük Obsidian. In Ian Hodder (ed.). Substantive Technologies at Çatalhöyük. Reports for the 2000-2008 Seasons. Çatalhöyük Research Project Series Volume 9, Chapter 21: The Chipped Stone, Appendix 21.1, pp 1-7. British Institute at Anakara and the Cotsen Insitute of Archaeology at UCLA.

Munchaev, P.M., Amirov, S.H. 2009. “Взаимосвязи Кавказа и Месопотамии в VI-IV тыс. до н.э.”, Кавказ: Археология и Этнология. Международная научная конференция. Материалы конференции. 11-12 сентября, 2008, Азербайджан, Шамкир, НАН Азербайджана, Институт археологии и этнографии, М. Н. Рагимова (ed.), Баку: Чашыоглу.

Nadooshan, K., Abedi, F.A., Glascock, M.D., Eskandari, N., Khazaee, M. 2013. Provenance of prehistoric obsidian artefacts from Kul Tepe, northwestern Iran using X-ray fluorescence analysis. Journal of Archaeological Science 40(4): 1956-1965. 
Nasedkin, V.V., Formozov, A.A. 1965. Vulkanicheskoe steklo iz stoyanok kamennogo veka Krasnodarskogo kraya I Checheno-Ingushetii. In: Arkheologiya i Estectvenniye Nauki, B.A. Kolchin (editor), pp. 167-170. Moscow: Nauka.

Nash, B.P., Merrick, H.V., Brown, F.H. 2011. Obsidian types from Holocene sites around Lake Turkana, and other localities in northern Kenya. Journal of Archaeological Science 38:13711376.

Nelson, D.E., D'Auria, J.M., Bennett, R.B. 1975. Characterization of Pacific Northwest Coast Obsidian by X-ray Fluorescence Analysis. Archaeometry 17:85-97.

Oddone, M., Bigazzi, G., Keheyan, Y., Meloni, S. 2000. Characterisation of Armenian Obsidians: Implications for Raw Material Supply for Prehistoric Artifacts. Journal of Radioanaytical and Nuclear Chemistry 243(3):673-682.

Orange, M., Carter, T., Le Bourdonnec, F.-X. 2013. Sourcing obsidian from Tell Aswad and Qdeir 1 (Syria) by SEM-EDS and EDXRF: Methodological implications. Comptes Rendus Palevol 12(3):173-180.

Özdoğan, M. 2007. Amidst Mesopotamia-centric and Euro-centric approaches: the changing role of the Anatolian peninsula between the East and the West. Anatolian Studies 57:17-24.

Palumbi G., Gratuze B., Harutunyan A., Chataigner C. 2014. Obsidian-tempered pottery in the Southern Caucasus: a new approach to obsidian as a ceramic-temper. Journal of Archaeological Science 44, 43-54.

Palumbi, G. 2008. The Red and Black. Social and Cultural Interaction between the Upper Euphrates and Southern Caucasus Communities in the Fourth and Third Millennium BC. Studi di Preistoria Orientale 2. Sapienza Università di Roma.

Paz, S. 2009. A Home Away from Home? The Settlement of Early Transcaucasian Migrants at Tel Bet Yerah. Tel Aviv 36(2): 196-217.

Pernicka, E. 1992. Herkunftsbestimmung späturukzeitlicher obsidianfunde vom Hassek Höyük. Istanbuler Forschungen 38, 124-131.

Pernicka, E., Keller, J., Cauvin, M.C., 1997. Obsidian from Anatolian sources in the Neolithic of the Middle Euphrates region (Syria). Paléorient 23, 113-122.

Pitskhelauri, K. 2012. Uruk Migrants in the Caucasus. Bulletin of the Georgian National Academy of Sciences 6(2):153-161. 
Poidevin, J.L. 1998. Les gisements d’obsidienne de Turquie et de Transcaucasie: géologie, géochimie et chronométrie, in: Cauvin, M.-C., Gourgaud, A., Gratuze, B., Arnaud, N., Poupeau, G., Poidevin, J.L., Chataigner, C. (Eds.), L'obsidienne au Proche et Moyen-Orient: Du Volcan à l'Outil. BAR, Oxford, pp. 105-167.

Pollock, S. 2013. The Circulation of People and Knowledge in Uruk Mesopotamia. In Elke Kaiser and Wolfram Schier (Eds.), Mobilität und Wissenstransfer in diachroner und interdisziplinärer Perspektive, De Gruyter, pp. 83-102.

Potts, D.T. 2013. Mesopotamian and Persian migrations. The Encyclopedia of Global Human Migration. DOI: 10.1002/9781444351071.wbeghm364.

Poupeau, G., Le Bourdonnec, F.-X., Carter, T., Delerue, S., Shackley, M.S., Barrat, J., Dubernet, S., Moretto, P., Calligaro, T., Milić, M., Kobayashi, K. 2010. The use of SEM-EDS, PIXE and EDXRF for obsidian provenance studies in the Near East: a case study from Neolithic Çatalhöyük (central Anatolia). Journal of Archaeological Science 37:2705-2720.

Pustovoytov, K., Deckers, K., Goldberg, P. 2011. Genesis, age and archaeological significance of a pedosediment in the depression around Tell Mozan, Syria. J. Archaeol. Sci. 38, 913-924.

Reed, S.J.B. 2005. Electron Microprobe Analysis and Scanning Electron Microscopy in Geology. 2nd ed. Cambridge University Press.

Renfrew, C., Dixon, J. 1976. Obsidian in Western Asia: A Review. Problems in Economics and Social Archaeology 42:137-150.

Renfrew, C., Dixon, J., Cann, J. 1966. Obsidian and Early Cultural Contact in the Near East. Proceedings of the Prehistoric Society 2, 30-72.

Renfrew, C., Dixon, J., Cann, J. 1968. Further Analysis of Near Eastern Obsidians. Proceedings of the Prehistoric Society 34, 319-331.

Rosen, S., Tykot, R., Gottesman, M. 2005. Long distance trinket trade: Early Bronze Age obsidian from the Negev. Journal of Archaeological Science 32, 775-784.

Rothman, M.S. 2003. Ripples in the stream: Transcaucasia-Anatolian interaction in the Murat/Euphrates Basin at the beginning of the third millennium B.C. In: Archaeology in the Borderlands: Investigations in Caucasia and Beyond, eds Smith, A., Rubinson, K. (Cotsen Institute of Archaeology, UCLA, pp. 95-110. 
Rothman, M.S. 2015. Early Bronze Age migrants and ethnicity in the Middle Eastern mountain zone. PNAS 112(30):9190-9195.

Sanna, I., Le Bourdonnec, F.-X., Poupeau, G., Luglie, C., 2010. Ossidiane non sarde in Sardegna. Analisi di un rinvenimento subacqueo nel Porto di Cagliari. In L'ossidiana del Monte Arci nel Mediterraneo, Pau, Italy, 27-29 June 2008, pp. 99-119.

Saunders, N. 2001. A Dark Light: Reflections on Obsidian in Mesoamerica. World Archaeology 33:220-236.

Schechter, H.C., Marder, O., Barkai, R., Getzov, N., Gopher, A. 2013. The obsidian assemblage from Neolithic Hagoshrim, Israel: pressure technology and cultural influence. In Stone Tools in Transition: From Hunter-Gatherers to Farming Societies in the Near East, edited by Ferran Borrell, Juan José Ibáñez, and Miquel Molist, pp. 509-527. Universitat Autònoma de Barcelona.

Schwartz, M., Erdman, K., Morison, M. 2009. Migration, Diffusion and Emulation: Petrographic Comparisons of Early Transcaucasian and Anatolian Pottery from Malatya-Elazıg, Turkey. Ancient Near Eastern Studies 46: 138-159.

Shackley, M.S. 1988. Sources of Archaeological Obsidian in the Southwest: An Archaeological, Petrological, and Geochemical Study. American Antiquity 53(4): 752-772.

Shackley, M.S. 1995. Sources of Archaeological Obsidian in the Greater American Southwest: An Update and Quantitative Analysis. American Antiquity 60(3):531-551.

Shackley, M.S. 1998. Archaeological Obsidian Studies: Method and Theory. Springer.

Shackley, M.S. 2005. Obsidian: Geology and Archaeology in the North American Southwest. University of Arizona.

Shackley, M.S. 2011. An Introduction to X-Ray Fluorescence (XRF) Analysis in Archaeology. In X-Ray Fluorescence Spectrometry (XRF) in Geoarchaeology (M.S. Shackley, editor), Springer, pp. 7-44.

Skinner, C. 1995. IAOS Bibliography hits internet hyperspace on the World Wide Web. IAOS Bulletin 13: 2-3.

Smith, R.L. 2008. Premodern Trade in World History. Routledge.

Stein, D.L. 1997. Hurrians. In The Oxford Encyclopedia of Archaeology in the Near East, edited by E.M. Meyers, pp. 126-130. Oxford University Press.

Stein, G.J. 2001. Rethinking World-Systems: Diasporas, Colonies, and Interaction in Uruk Mesopotamia. 
University of Arizona Press.

Steinkeller, P. 1998. The Historical Background of Urkesh and the Hurrian Beginnings in Northern Mesopotamia. In Urkesh and the Hurrians, Studies in Honour of Lloyd Costen, edited by G. Buccellati and M. Kelly-Buccellati, pp. 75-98. Undena Publications.

Thomalsky, J., 2013. Large blade technologies in the Transaucasus and Northern Mesopotamia from 6-4th Millennium BC. In: At the Northern Frontier of Near Eastern Archaeology Conference, Venice, 9-11 January 2013.

Thomsen, C.J. 1936. Kortfattet udsigt over midesmaeker og oldsager fra Nordens oldtid". In Rafn, C.C. (ed.) Ledetraad til Nordisk Oldkyndighed (in Danish). Copenhagen: Kongelige Nordiske Oldskriftselskab.

Tykot, R.H. 1995. Prehistoric Trade in the Western Mediterranean: The Sources and Distribution of Sardinian Obsidian. PhD dissertation, Harvard University.

Tykot, R.H. 1997. Characterization of the Monte Arci (Sardinia) Obsidian Sources. Journal of Archaeological Science 24(5):467-479.

Tykot, R.H., Chia, S., 1997. Long-distance obsidian trade in Indonesia. In: Vandiver, P., Druzik, J., Merkel, J., Stewart, J. (eds.), Materials Issues in Art and Archaeology V. Materials Research Society, Pittsburgh, pp. 175-180.

Ur, J.A. 2010. Cycles of Civilization in Northern Mesopotamia, 4400-2000 BC. J. Archaeol. Res. 18:387-431.

von Dassow, E. 2008 State and Society in the Late Bronze Age Alalah under the Mittani Empire. Studies on the Civilization and Culture of Nuzi and the Hurrians 17. CDL Press, Bethesda.

Wada, K., 2009. Petrologic Model of Shirataki Obsidian, Northern Hokkaido, Japan: Its Structure, Composition and the Origin. In Geological Society of America Abstracts with Programs, pp. 553. vol. 41, Portland, Oregon. Geological Society of America.

Wagner G.A., Weiner K.L. 1987. Deutches Archaeologisches Institut Demircihoyuk. Die Ergebenisse des Ausgrabungen 1975-1978. In: Herausgegeben von Manfred Korfmann Band II:

Naturwissenschaftliche Untersuchungen, Verlag Philipp von Zabern, Mainz, Germany, pp. 26-29.

Weisler, M.I., Clague, D.A., 1998. Characterisation of Archaeological Volcanic Glass from Oceania: The Utility of Three Techniques. In Archaeological Obsidian Studies: Method and Theory, M.S. Shackley (ed.), pp. 103-128. Society for Archaeological Sciences. 
Wilhelm, G. 1989. The Hurrians. Aris \& Phillips.

Wilkinson, T.J., Galiatsatos, N., Lawrence, D., Ricci, A., Dunford, R., Philip, G. 2012. Late Chalcolithic and Early Bronze Age Landscapes of Settlement and Mobility in the Middle Euphrates: A Reassessment. Levant 44(2): 139-185.

Williams-Thorpe, 0., 1995. Obsidian in the Mediterranean and the Near East: a provenancing success story. Archaeometry 37, 217-248.

Wright, G.A. 1969. Obsidian Analyses and Prehistoric Near Eastern Trade: 7500 to 3500 B.C. Anthropological Papers, Museum of Anthropology, University of Michigan 37. 


\begin{tabular}{|c|c|c|c|c|c|c|c|c|c|c|c|c|c|c|c|}
\hline & SiO2 & Al2O3 & $\mathrm{Fe} 2 \mathrm{O} 3$ & MgO & $\mathrm{CaO}$ & $\mathrm{Na2O}$ & $\mathrm{K} 2 \mathrm{O}$ & $\mathrm{MnO}$ & $\mathrm{Ti}$ & $\mathrm{Rb}$ & Sr & $Y$ & $\mathrm{Zr}$ & $\mathrm{Nb}$ & $\mathrm{Ba}$ \\
\hline & mean $\pm \sigma$ & mean $\pm \sigma$ & mean $\pm \sigma$ & mean $\pm \sigma$ & mean $\pm \sigma$ & mean $\pm \sigma$ & mean $\pm \sigma$ & mean $\pm \sigma$ & mean $\pm \sigma$ & mean $\pm \sigma$ & mean $\pm \sigma$ & mean $\pm \sigma$ & mean $\pm \sigma$ & mean $\pm \sigma$ & mean $\pm \sigma$ \\
\hline \multicolumn{16}{|c|}{ Poidevin data in Healey 2000 (select elements): } \\
\hline DT 499/1 & 75.30 & 12.90 & 0.83 & 0.15 & 0.62 & 3.92 & 4.29 & 0.08 & 489 & 110 & 30 & 19 & 70 & 26 & 341 \\
\hline DT $1774 / 77$ & 75.80 & 13.20 & 0.79 & 0.13 & 0.63 & 4.00 & 4.32 & 0.08 & 494 & 110 & 31 & 19 & 71 & 27 & 344 \\
\hline DT 633/1 & 75.50 & 13.20 & 0.83 & 0.18 & 0.73 & 4.11 & 4.37 & 0.08 & 528 & 111 & 36 & 19 & 75 & 25 & 397 \\
\hline DT 683/3 & 75.60 & 13.20 & 0.88 & 0.17 & 0.67 & 4.11 & 4.41 & 0.08 & 578 & 106 & 44 & 17 & 80 & 23 & 512 \\
\hline DT 2414/4 & 75.70 & 13.30 & 0.79 & 0.17 & 0.70 & 3.77 & 4.07 & 0.09 & 472 & 107 & 29 & 18 & 67 & 25 & 317 \\
\hline DT $1237 / 7$ & 73.20 & 12.80 & 1.12 & 0.19 & 0.73 & 3.85 & 3.89 & 0.09 & 465 & 116 & 22 & 20 & 65 & 27 & 216 \\
\hline DT $1244 / 21$ & 75.90 & 13.30 & 0.73 & 0.14 & 0.78 & 4.19 & 4.44 & 0.07 & & & & & & & \\
\hline Mean & \#\#\# \pm \#\#t & \#\#\# \pm \#\# & $0.85 \pm \# \#$ & $0.16 \pm \ldots \# t$ & $0.69 \pm \pm$ & 3.99 & 4.26 & 0.08 & 504 & 110 & 32 & 1 & & 26 & 354 \\
\hline
\end{tabular}

\section{Arteni data in Poidevin 1998.}

Arteni A $\quad 76.27$

\begin{tabular}{ll} 
Arteni B $\quad 76.05$ \\
\hline
\end{tabular}

13.44

Arteni C $\quad 76.34$

13.41

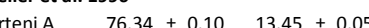

$\begin{array}{lll}\text { Arteni B } & 76.44 \pm 0.08 & 13.43 \pm 0.04\end{array}$

$\begin{array}{ll}0.55 & 0.07 \\ 0.55 & 0.06\end{array}$

\subsection{7}

0.15

$.54 \pm 0.01 \quad 0.07 \pm 0.01$ $0.53 \pm 0.01 \quad 0.06 \pm 0.01$

$0.06 \pm 0.01 \quad 0.52 \pm 0.01$

\section{Arteni data for Frahm collection:}

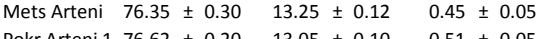

Pokr Arteni $276.74 \pm 0.18 \quad 12.99 \pm 0.06$

pXRF - Minnesota

Mets Arten

Pokr Arteni 2

EDXRF - MURR

Mets Arteni

Pokr Arteni 1

(1)

$4.26 \pm 0.16$

$4.17 \pm 0.07$
$4.06 \pm 0.03$

$4.58 \pm 0.25$

$0.06 \pm 0.00$

$0.53 \pm 0.04$

$0.53 \pm 0.03$
$0.52 \pm 0.02$

$0.54 \pm 0.03$
$0.59 \pm 0.02$

Pokr Arteni 2

$0.63 \pm 0.01$

$4.68 \pm 0.06 \quad 0.07 \pm 0.00$

$4.20 \pm 0.26 \quad 0.08 \pm 0.00$

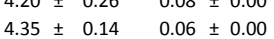

$4.49 \pm 0.03 \quad 0.06 \pm 0.00$

$4.49 \pm 0.02 \quad 0.07 \pm 0.00$

$4.48 \pm 0.10 \quad 0.05 \pm 0.00$

$0.49 \pm 0.01$

$0.74 \pm 0.02$

NAA - MURR

Pokr Arteni 1

$\begin{array}{ll}13.70 \pm 0.41 & 0.48 \pm 0.01 \\ 13.77 \pm 0.25 & 0.56 \pm 0.01\end{array}$

Pokr Arteni 1

$12.17 \pm 0.15 \quad 0.60 \pm 0.00$

Mean values

Mets Arteni \#\#\#\#

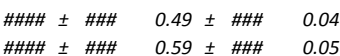

Pokr Arteni 1 \#\#\#

\#\#\#\# \pm \#\#\# $0.62 \pm \# \# \quad 0.06$

\section{Other Arteni dato}

Chataigner and Gratuze 2014a

$\begin{array}{llllll}\text { Arteni } 1 & 75.4 \pm 0.8 & 13.6 \pm 1.2 & 0.47 \pm 0.06 \\ \text { Arteni } 2 & 75.2 \pm & 0.0 & 0.0\end{array}$

Arteni $3 \quad 760 \pm 1.1$

$13.1 \pm 0.3 \quad 0.55 \pm 0.03$

$0.05 \pm 0.00 \quad 0.54 \pm 0.06$

$0.08 \pm 0.03-0.53 \pm 0.07$

$\begin{array}{lllll}4.17 \pm 0.10 & 4.42 \pm 0.21 & 0.10 \pm 0.00 \\ 4.11 & \pm 0.02 & 4.45 \pm 0.15 & 0.08 \pm 0.00\end{array}$

$\begin{array}{llll}4.11 \pm 0.02 & 4.45 \pm 0.15 & 0.08 \pm 0.00 \\ 4.07 \pm 0.03 & 4.75 \pm 0.04 & 0.07 \pm 0.00\end{array}$

$0.51 \pm 0.03$

$4.22 \pm 0.13$

$4.42 \pm 0.19 \quad 0.08 \pm$ \#\#\#

$4.48 \pm 0.13 \quad 0.07 \pm \# \#$

$4.07 \pm 0.01$

$76.0 \pm 1.1$

$13.1 \pm 0.1 \quad 0.60 \pm 0.06 \quad 0.08 \pm 0.03$

$\begin{array}{llll}4.03 \pm 0.01 & 4.39 \pm 0.11 & 0.07 \pm 0.00\end{array}$

$331 \pm 15$
$440 \pm 33$

$526 \pm 29$

$143 \pm 7$
$122 \pm 10$

$122 \pm 10$

$\begin{array}{r}8 \pm \\ 14 \pm \\ \hline\end{array}$

$16 \pm 1$
+3

$16 \pm 1$
$15 \pm 2$

$\begin{array}{rrr}36 \pm 3 & 36 \pm 3 & 30 \pm 4 \\ 48 \pm 3 & 28 \pm 2 & 142 \pm 10\end{array}$

$52 \pm 8$

$27 \pm 1 \quad 72 \pm 13$

$50 \pm 3 \quad 34 \pm 2 \quad 46 \pm 31$

$64 \pm 3 \quad 26 \pm 1 \quad 204 \pm 50$

$\begin{array}{lll}70 \pm 2 & 24 \pm 1 & 398 \pm 16\end{array}$

$86 \pm 8 \quad 38 \pm 2$

$88 \pm 3$

$38 \pm 13 \quad 31 \pm 8$

$\begin{array}{ll}56 \pm 8 & 151 \pm 48 \\ 64 \pm 9 & 350 \pm 17\end{array}$

$50 \pm 6 \quad 36 \pm 2 \quad 50 \pm 17$

$64 \pm 17-28 \pm 2 \quad 186 \pm 31$

$72 \pm 17 \quad 26 \pm 2 \quad 387 \pm 32$ 
Pokr Arteni 1

Domuztepe artifact: $\quad$ DT 09 I.4869/1 Geological specimens:

AR.2009.4.1

AR.2009.4.2

AR.2009.5.1A

AR.2009.5.1B

AR.2009.5.1C

AR.2009.32.1

AR.2009.32.2

AR.2009.41.1

AR.2009.41.2

AR.2009.42.1

AR.2009.42.2

AR.2009.68.1

AR.2009.68.2

AR.2009.68.4

AR.2009.68.6

Pokr Arteni 2

Domuztepe artifacts: DT $051.3891 / 32$ DT 05 I.3919/1 DT 05 I.3919/2 DT 05 I.3920/4 DT 05 I.3976/1 DT 05 I.3976/2 DT 05 I.4025/1 DT 05 I.4047/1 DT 05 I.4052/1 DT 99 I.2463/2 DT 99 I.2495/10

\begin{tabular}{|c|c|c|c|c|c|c|c|c|c|c|c|}
\hline $\mathrm{SiO}_{2}$ & $\mathrm{TiO}_{2}$ & $\mathbf{A l}_{2} \mathbf{O}_{3}$ & $\mathrm{FeO}_{(\mathrm{T})}$ & Mno & MgO & $\mathrm{CaO}$ & $\mathrm{Na}_{2} \mathrm{O}$ & $\mathbf{K}_{2} \mathbf{O}$ & $\mathrm{Zr}$ & $\mathbf{Z n}$ & $\mathrm{Ba}$ \\
\hline 76.66 & 0.0720 & 13.26 & 0.473 & 0.0703 & 0.0500 & 0.5167 & 4.216 & 4.613 & 0.0059 & 0.0064 & 0.0123 \\
\hline 76.71 & 0.0783 & 13.15 & 0.478 & 0.0767 & 0.0482 & 0.5093 & 4.150 & 4.584 & 0.0041 & 0.0087 & 0.0163 \\
\hline 76.62 & 0.0820 & 13.02 & 0.438 & 0.0733 & 0.0553 & 0.5277 & 4.186 & 4.757 & 0.0034 & 0.0087 & 0.0220 \\
\hline 76.89 & 0.0742 & 13.18 & 0.490 & 0.0761 & 0.0478 & 0.5238 & 4.248 & 4.533 & 0.0045 & 0.0102 & 0.0157 \\
\hline 76.81 & 0.0765 & 13.03 & 0.433 & 0.0799 & 0.0495 & 0.5345 & 4.198 & 4.767 & 0.0051 & 0.0116 & 0.0163 \\
\hline 76.61 & 0.0795 & 13.09 & 0.447 & 0.0689 & 0.0533 & 0.5266 & 4.097 & 4.759 & 0.0042 & 0.0106 & 0.0205 \\
\hline 76.39 & 0.0792 & 13.12 & 0.451 & 0.0733 & 0.0491 & 0.5109 & 4.190 & 4.677 & 0.0040 & 0.0100 & 0.0194 \\
\hline 76.73 & 0.0718 & 13.10 & 0.376 & 0.0776 & 0.0468 & 0.4682 & 4.205 & 4.381 & 0.0045 & 0.0075 & 0.0120 \\
\hline 76.73 & 0.0757 & 13.13 & 0.426 & 0.0786 & 0.0458 & 0.4571 & 4.259 & 4.644 & 0.0028 & .0064 & 0.0132 \\
\hline 76.44 & 0.0767 & 13.16 & 0.471 & 0.0773 & 0.0491 & 0.5120 & 4.257 & 4.631 & 0.0044 & 0.0099 & 0.0171 \\
\hline 76.47 & 0.0754 & 13.09 & 0.471 & 0.0743 & 0.0490 & 0.5151 & 4.181 & 4.594 & 0.0056 & 0.0098 & 0.0155 \\
\hline 76.37 & 0.0797 & 12.86 & 0.458 & 0.0721 & 0.0549 & 0.5219 & 4.203 & 4.651 & 0.0066 & 0.0093 & 0.0285 \\
\hline 76.27 & 0.0851 & 12.88 & 0.476 & 0.0699 & 0.0532 & 0.5086 & 4.156 & 4.671 & 0.0063 & 0.0083 & 0.0281 \\
\hline 76.73 & 0.0829 & 12.98 & 0.540 & 0.0702 & 0.0507 & 0.5218 & 4.122 & 4.652 & 0.0044 & 0.0073 & 0.0244 \\
\hline 77.02 & 0.0778 & 13.06 & 0.525 & 0.0732 & 0.0511 & 0.5159 & 4.153 & 4.578 & 0.0065 & 0.0051 & 0.0225 \\
\hline 76.58 & 0.0805 & 13.05 & 0.369 & 0.0684 & 0.0418 & 0.4665 & 4.090 & 4.740 & 0.0058 & 0.0064 & 0.0256 \\
\hline 76.48 & 0.0803 & 12.91 & 0.481 & 0.0738 & 0.0507 & 0.4550 & 3.961 & 4.888 & 0.0042 & 0.0056 & 0.0301 \\
\hline $\mathrm{SiO}_{2}$ & $\mathrm{TiO}_{2}$ & $\mathrm{Al}_{2} \mathbf{O}_{3}$ & $\mathrm{FeO}_{(\mathrm{T})}$ & MnO & MgO & $\mathrm{CaO}$ & $\mathrm{Na}_{2} \mathrm{O}$ & $\mathbf{K}_{2} \mathbf{O}$ & Zr & Zn & Ba \\
\hline 76.68 & 0.0922 & 12.98 & 0.539 & 0.0646 & 0.0501 & 0.5148 & 4.148 & 4.742 & 0.0070 & 0.0065 & 0.0391 \\
\hline 76.41 & 0.0901 & 12.96 & 0.564 & 0.0638 & 0.0624 & 0.5236 & 4.064 & 4.726 & 0.0078 & 0.0004 & 0.0362 \\
\hline 76.54 & 0.0849 & 13.00 & 0.493 & 0.0690 & 0.0616 & 0.5117 & 4.043 & 4.478 & 0.0075 & 0.0025 & 0.0358 \\
\hline 76.70 & 0.0922 & 13.07 & 0.367 & 0.0628 & 0.0590 & 0.5203 & 4.015 & 4.723 & 0.0071 & 0.0011 & 0.0391 \\
\hline 76.63 & 0.0988 & 13.00 & 0.413 & 0.0602 & 0.0667 & 0.5379 & 4.090 & 4.704 & 0.0073 & 0.0018 & 0.0413 \\
\hline 76.72 & 0.0918 & 12.97 & 0.461 & 0.0609 & 0.0642 & 0.5329 & 3.867 & 4.642 & 0.0076 & 0.0031 & 0.0364 \\
\hline 76.46 & 0.0943 & 12.95 & 0.459 & 0.0659 & 0.0650 & 0.5465 & 4.061 & 4.703 & 0.0078 & 0.0023 & 0.0396 \\
\hline 76.18 & 0.0868 & 12.88 & 0.478 & 0.0642 & 0.0624 & 0.5351 & 4.048 & 4.723 & 0.0074 & 0.0011 & 0.0359 \\
\hline 76.48 & 0.0888 & 12.88 & 0.529 & 0.0665 & 0.0628 & 0.5413 & 4.040 & 4.713 & 0.0085 & 0.0034 & 0387 \\
\hline 76.69 & 0.0831 & 13.09 & 0.426 & 0.0652 & 0.0627 & 5397 & 4.061 & 4.709 & 0.0075 & & 0.0382 \\
\hline 76.65 & 0.0902 & 13.03 & 0.322 & 0.0601 & 0.0579 & 0.5143 & 4.044 & 4.722 & 0.0079 & 0.0030 & 0.0324 \\
\hline 76.65 & 0.0876 & 13.07 & 0.398 & 0.0653 & 0.0591 & 0.5448 & 4.095 & 4.659 & 0.0075 & 0.0029 & 0.0355 \\
\hline
\end{tabular}




\begin{tabular}{|c|c|c|c|c|c|c|c|c|c|}
\hline & Total & Other source & Pasinler & Sarıkamış & Kars Arpacay & Pokr Arteni & Total Analyzed & Total Caucasus & $\%$ Caucasus \\
\hline Green & 3084 & 28 & & & & 0 & 28 & 0 & $0.0 \%$ \\
\hline Brown & 1266 & 14 & & & & 0 & 14 & 0 & $0.0 \%$ \\
\hline Brown tinge & 119 & 2 & & 2 & & 1 & 5 & 3 & $60.0 \%$ \\
\hline Grey & 2895 & 34 & 3 & 1 & & 1 & 39 & 5 & $12.8 \%$ \\
\hline Black & 1618 & 14 & & & 2 & 0 & 16 & 2 & $12.5 \%$ \\
\hline Red/Mahogany & 140 & 2 & 5 & & 1 & 19 & 27 & 25 & $92.6 \%$ \\
\hline Colorless & 200 & 0 & & & & 1 & 1 & 1 & $100.0 \%$ \\
\hline Other & 35 & 0 & & & & 0 & 0 & 0 & \\
\hline Total & 9357 & 95 & 8 & 3 & 3 & 22 & 131 & 36 & $27.5 \%$ \\
\hline
\end{tabular}



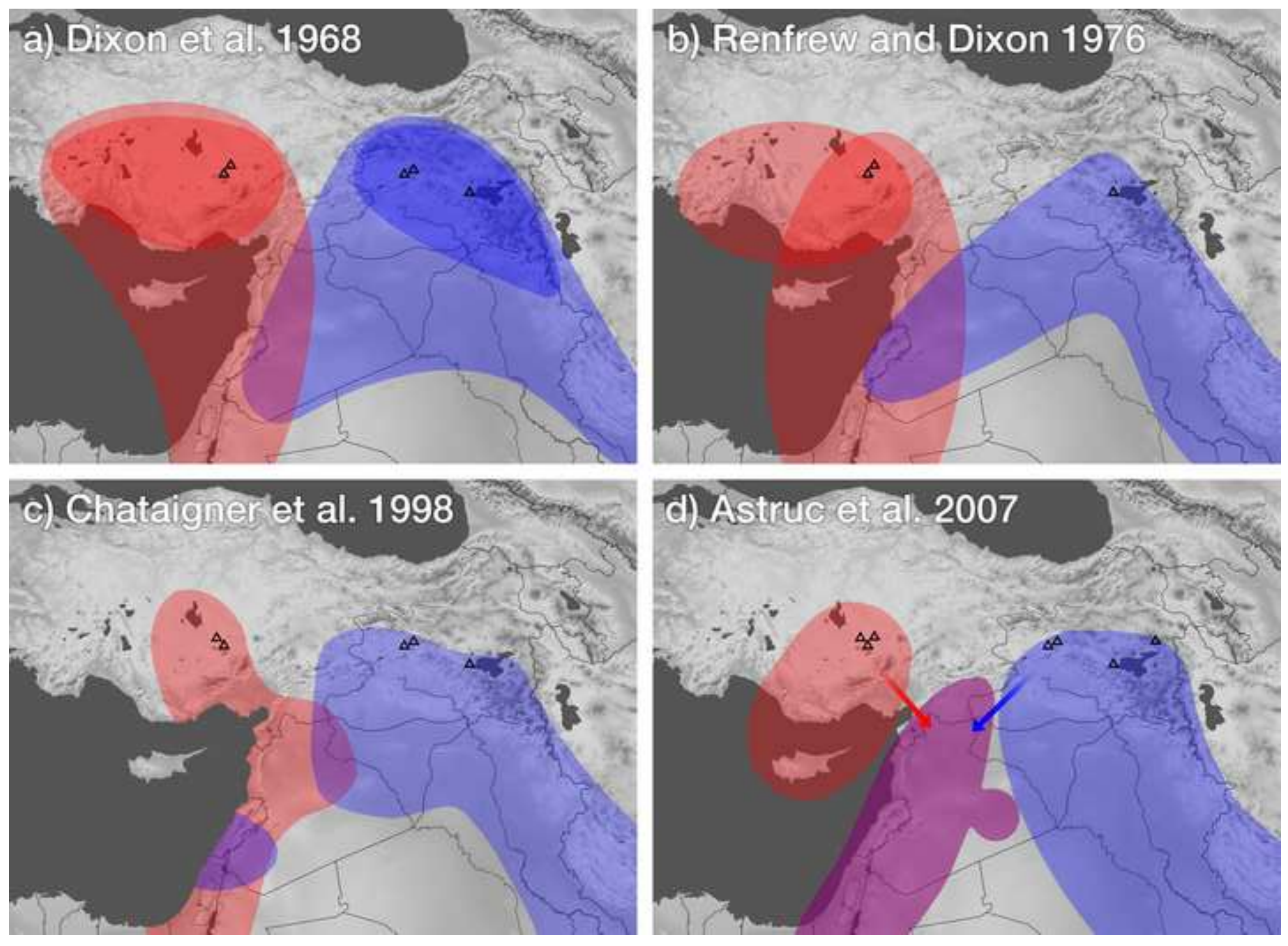

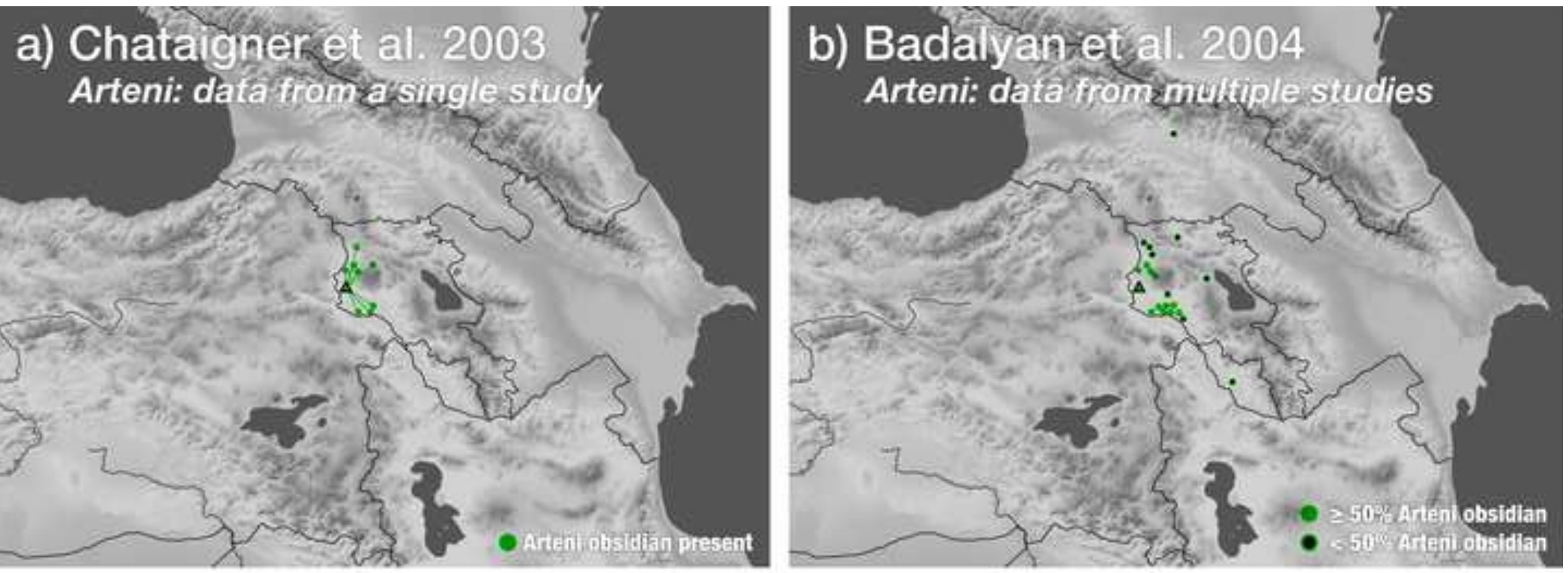

c) Chataigner: Barge $200 \overline{7}$ Arteni: least coss tpaith analys is

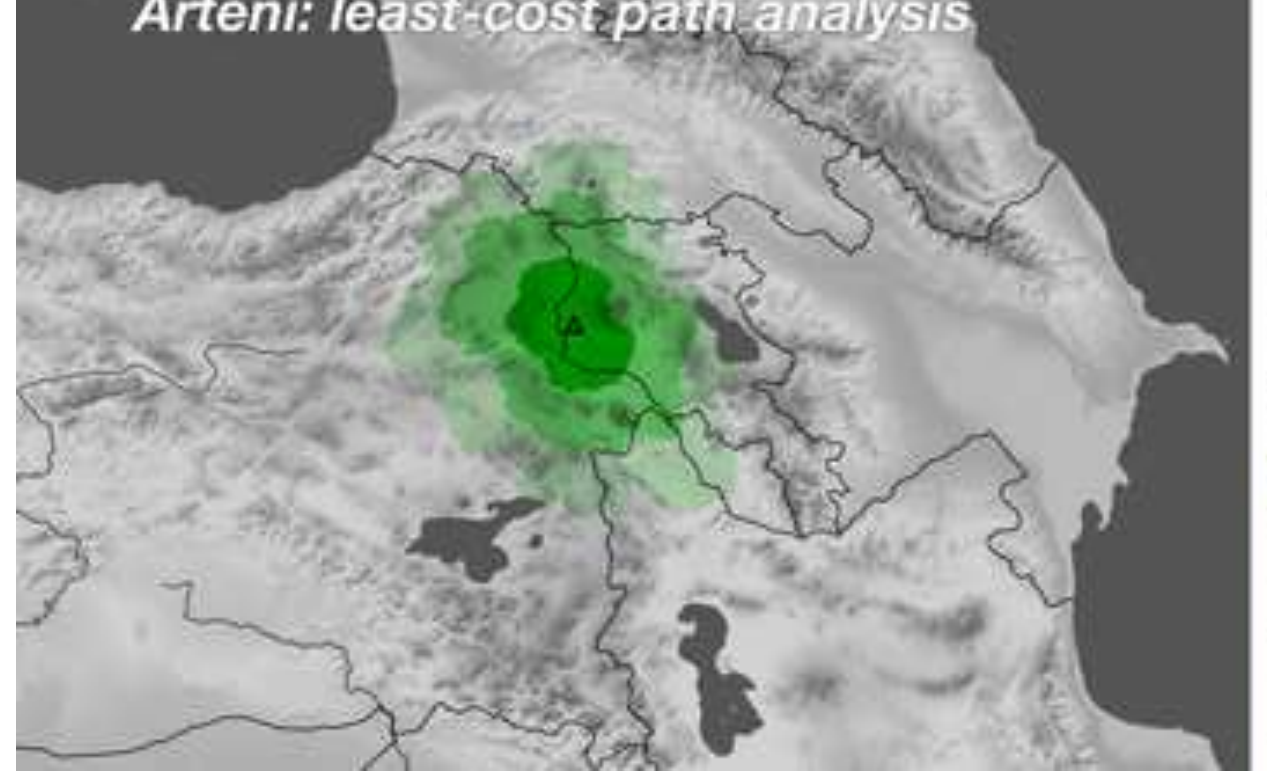

d) Arimura et al. 2010 Proposed distribution zones

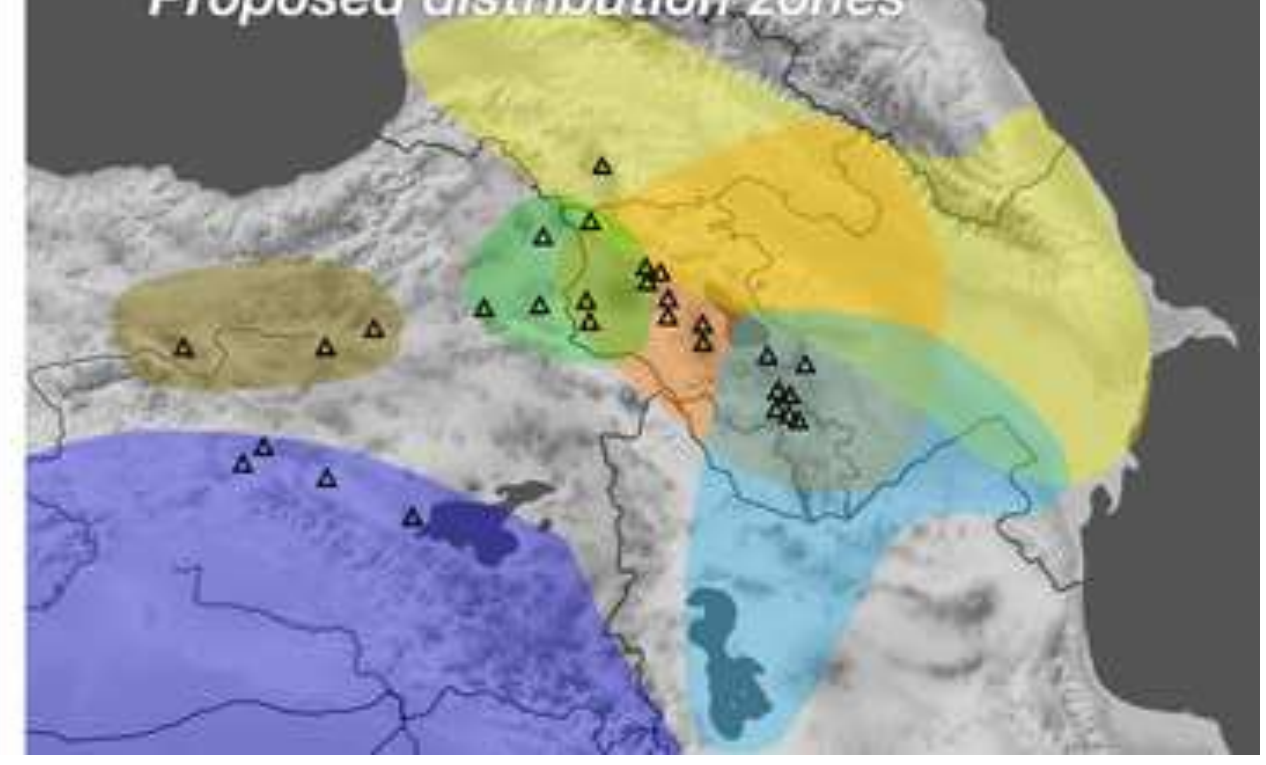



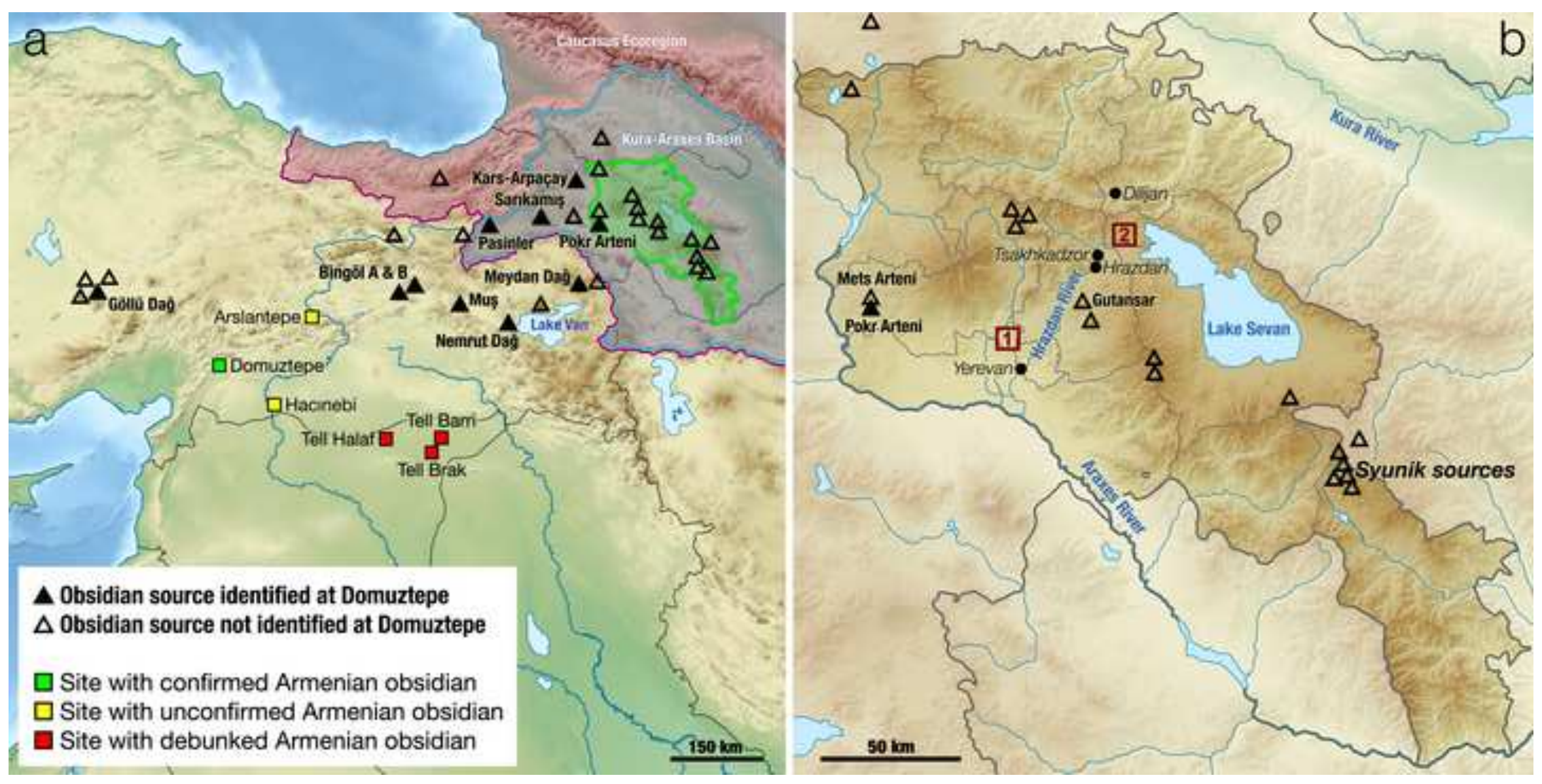




"Erevan" obsidian specimen

Gutansar volcanic complex

(1) Arteni (Pokr and Mets Arteni, Brusok)

- Syunik (Sevkar, Satanakar, Bazenk)

Gegham (Geghasar, Spitakasar)

O Tsakhkunyats (Damlik, Kamakar)

(1) Aghvorik (a.k.a. Ashotsk)

$\checkmark$ Hatis (Hatis 1 and 2) 

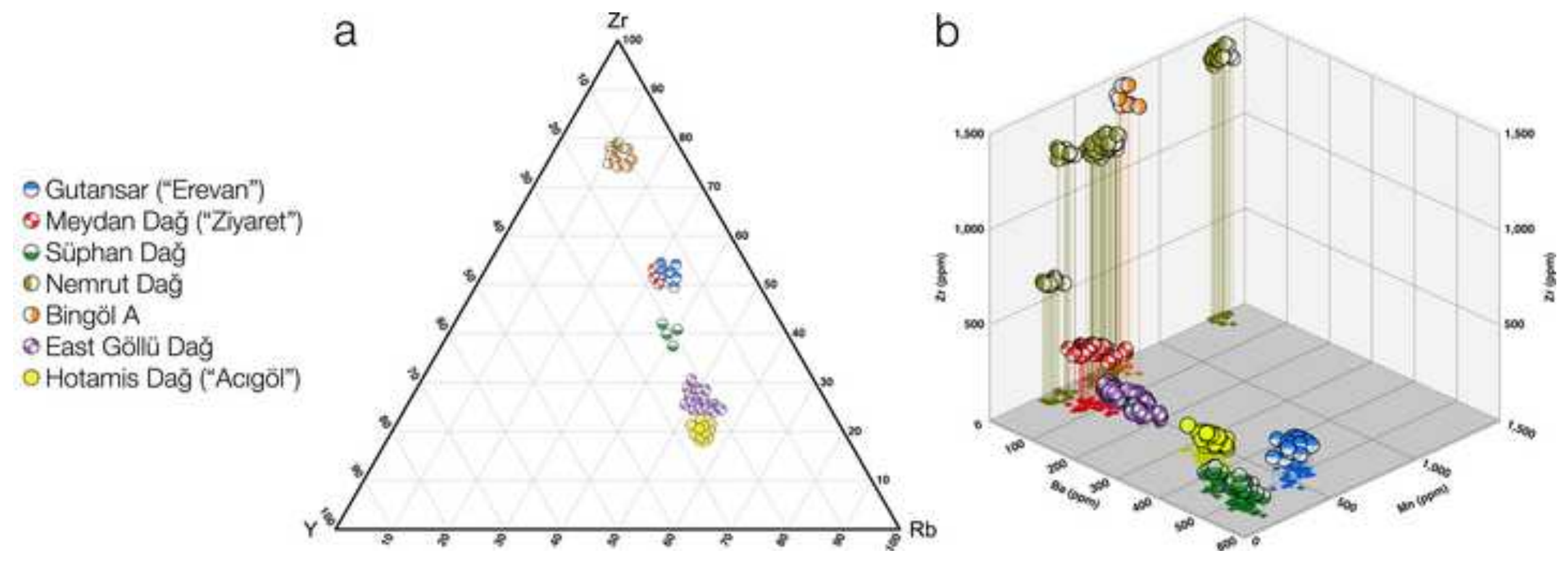

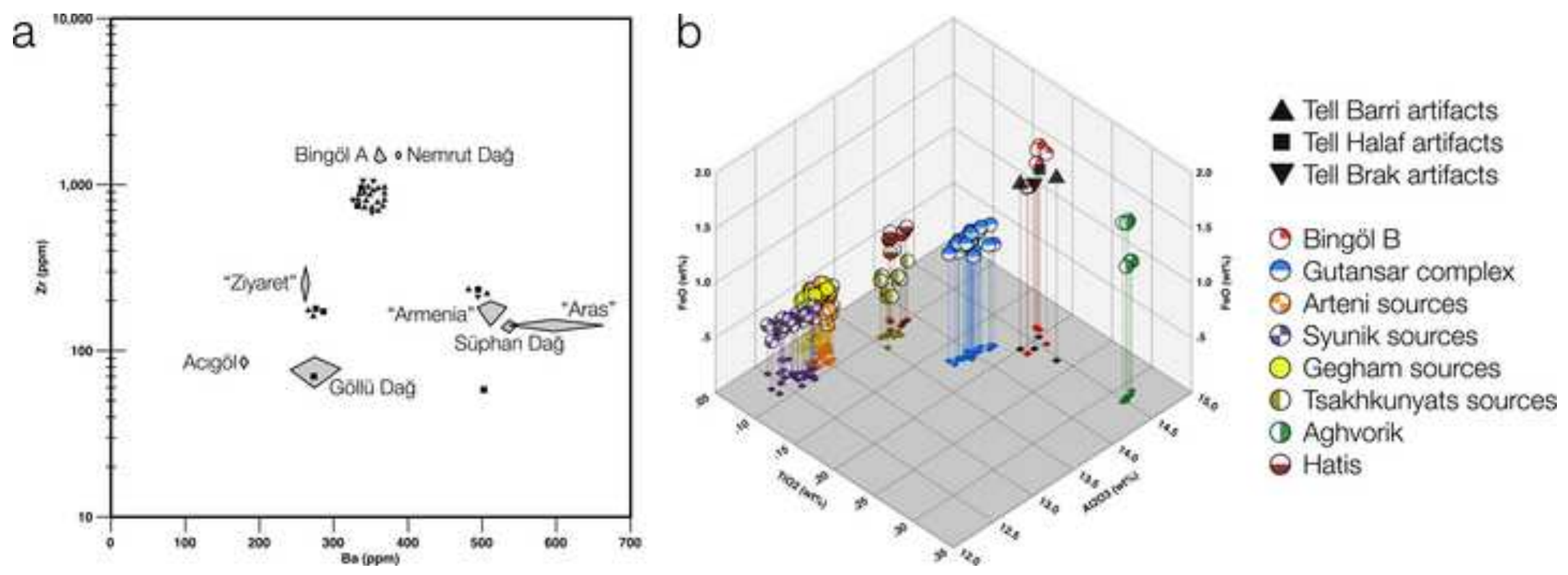
a

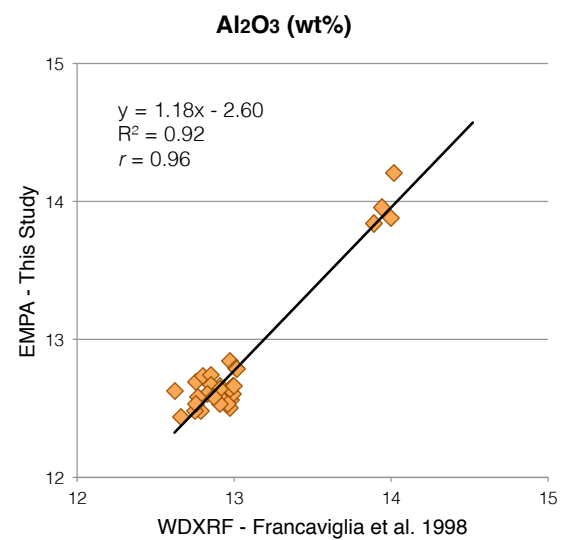

$\mathrm{CaO}(w t \%)$

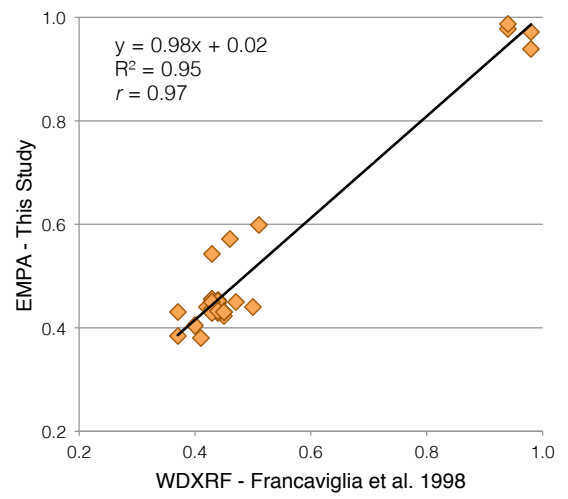

b



NAA - MURR Archaeometry Laboratory
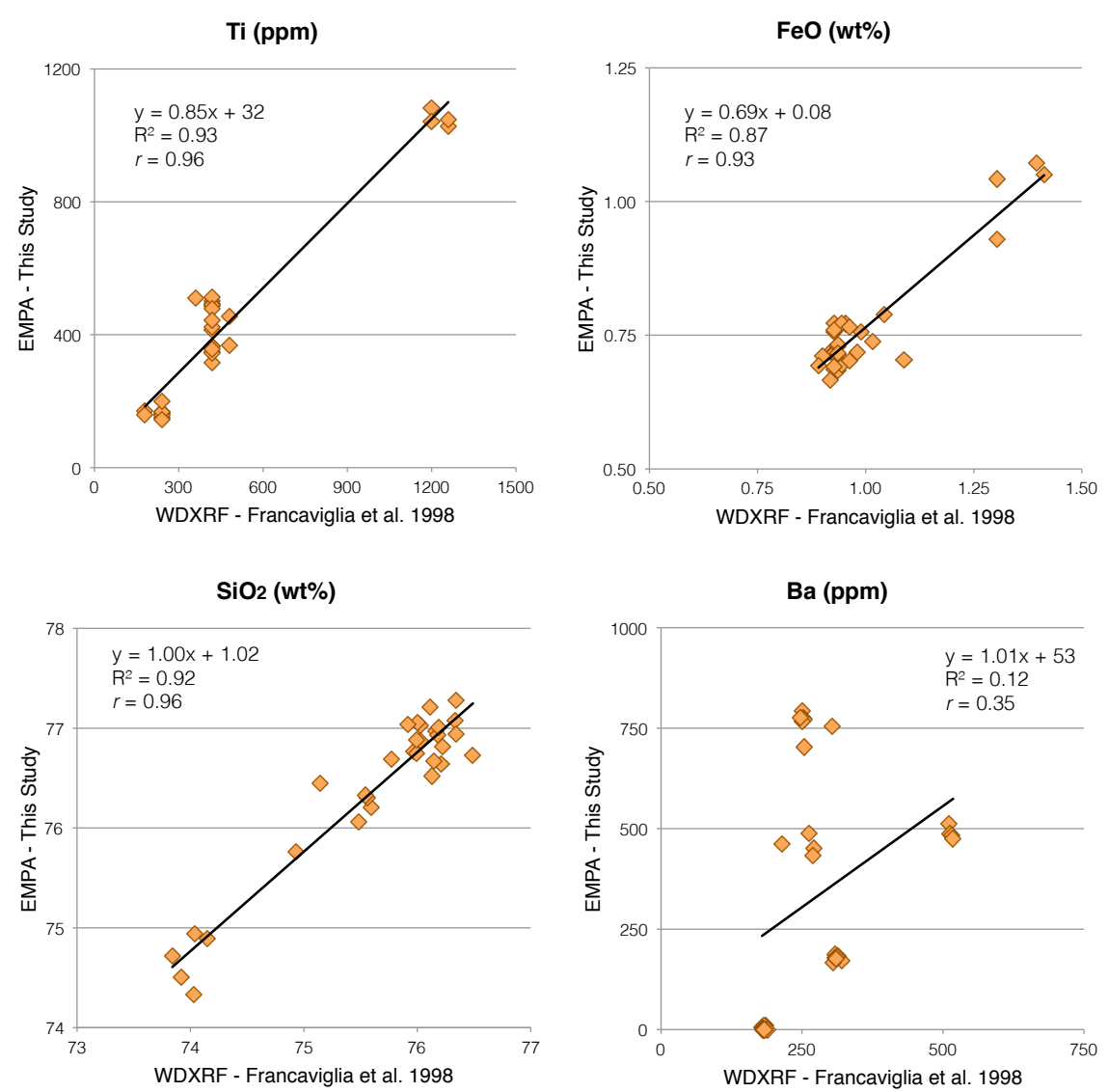

$\mathrm{Ba}(\mathrm{ppm})$

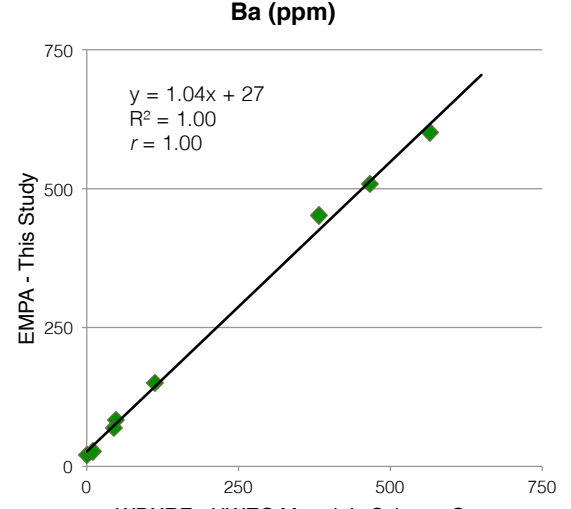

WDXRF - UWEC Materials Science Center

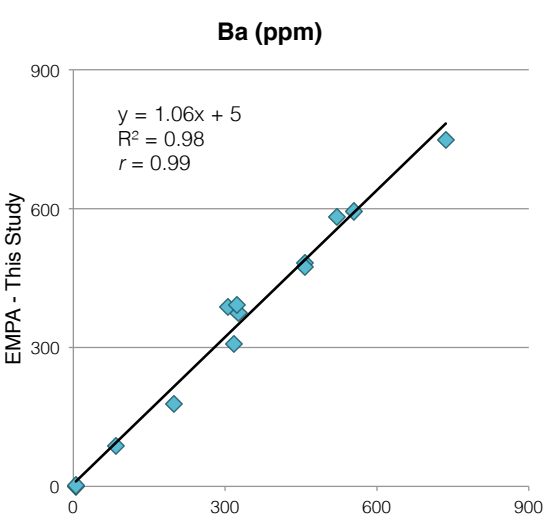

NAA - Institute for Nuclear Chemistry, Mainz 

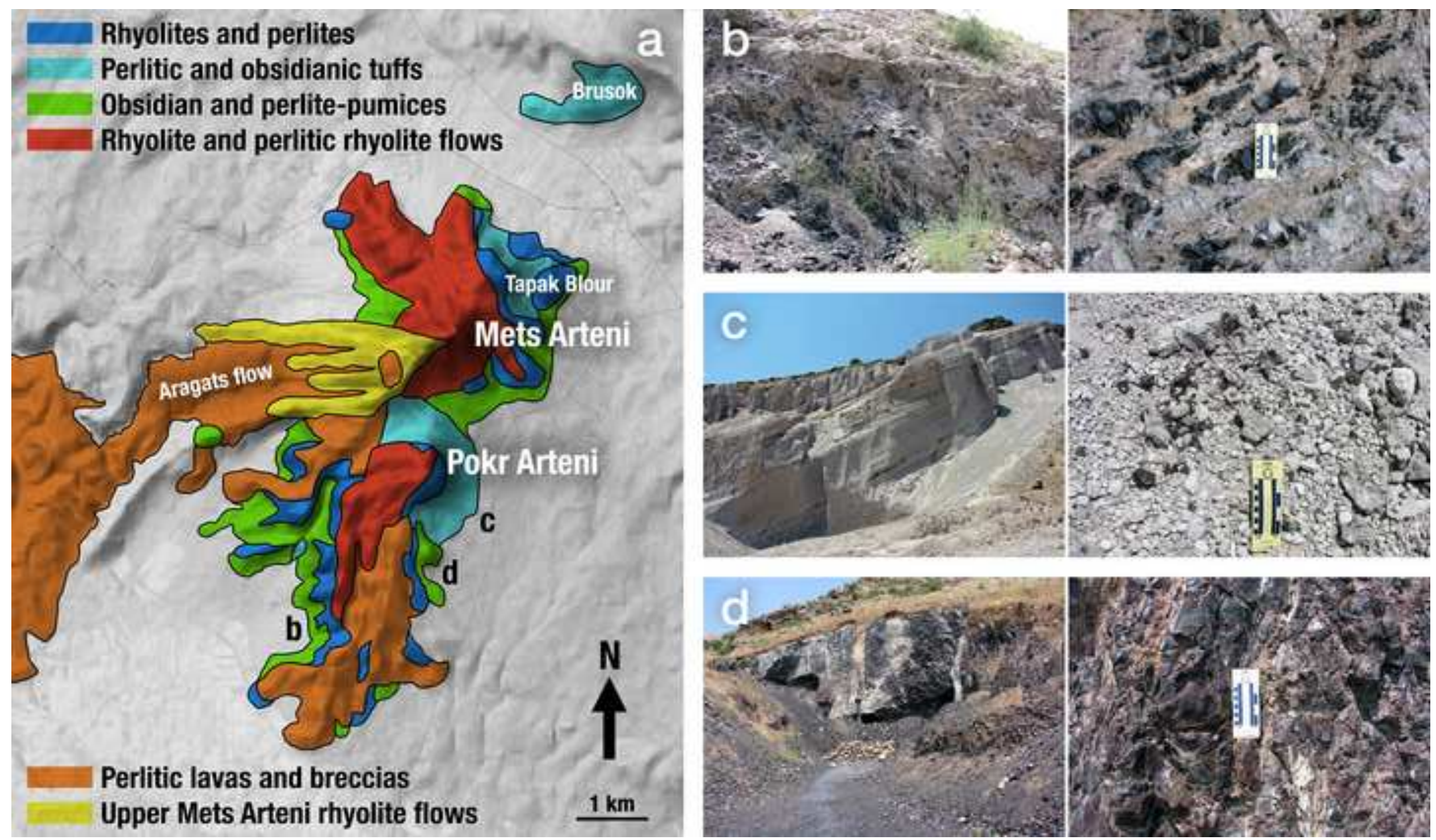


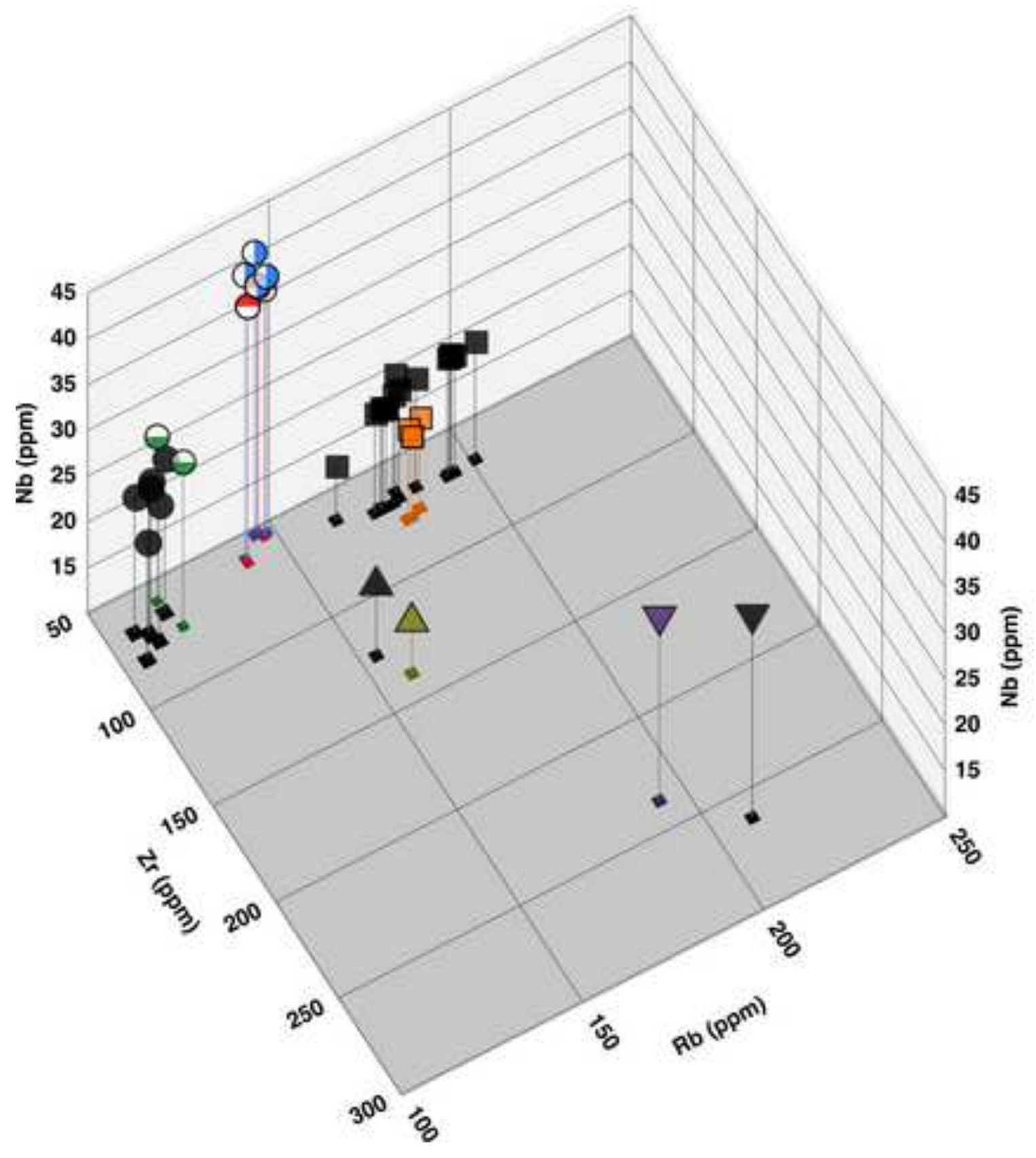

- Keller et al. - Arteni A

- Keller et al. - Arteni B

- Keller et al. - Arteni C

- Poidevin - Arteni artifacts

$\square$ Keller et al. - East Göllü Dağ

- Poidevin - East GD artifacts

$\triangle$ Keller et al. - Nenezi Dağ

$\Delta$ Poidevin - Nenezi Dağ artifacts

$\nabla$ Keller et al. - Meydan Dağ

$\nabla$ Poidevin - Meydan Dağ artifacts 

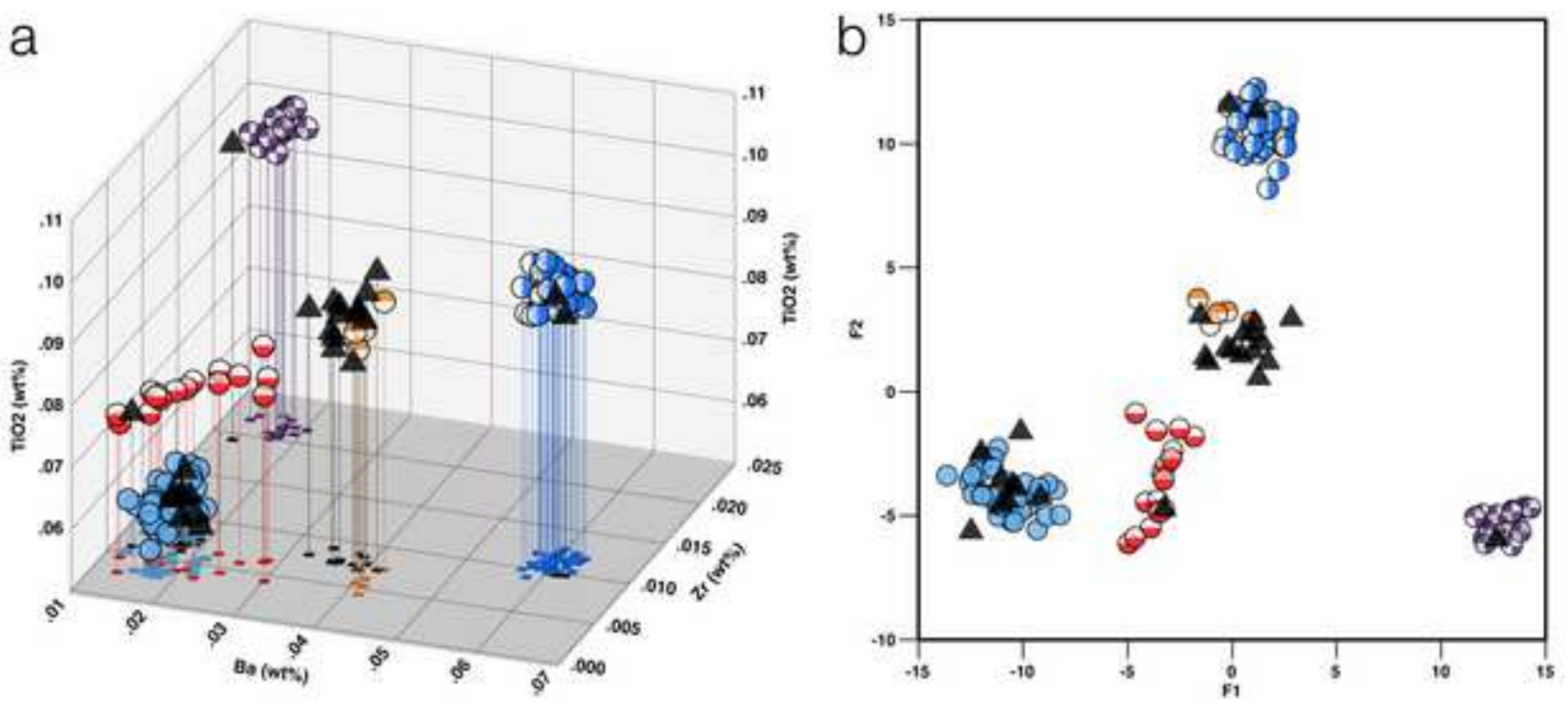

A Domuztepe

Poler Arteni 1

- Pokr Arteni 2

Golu Dag-East

(1) Kars-Avpaçay 2

(1) Senkams 


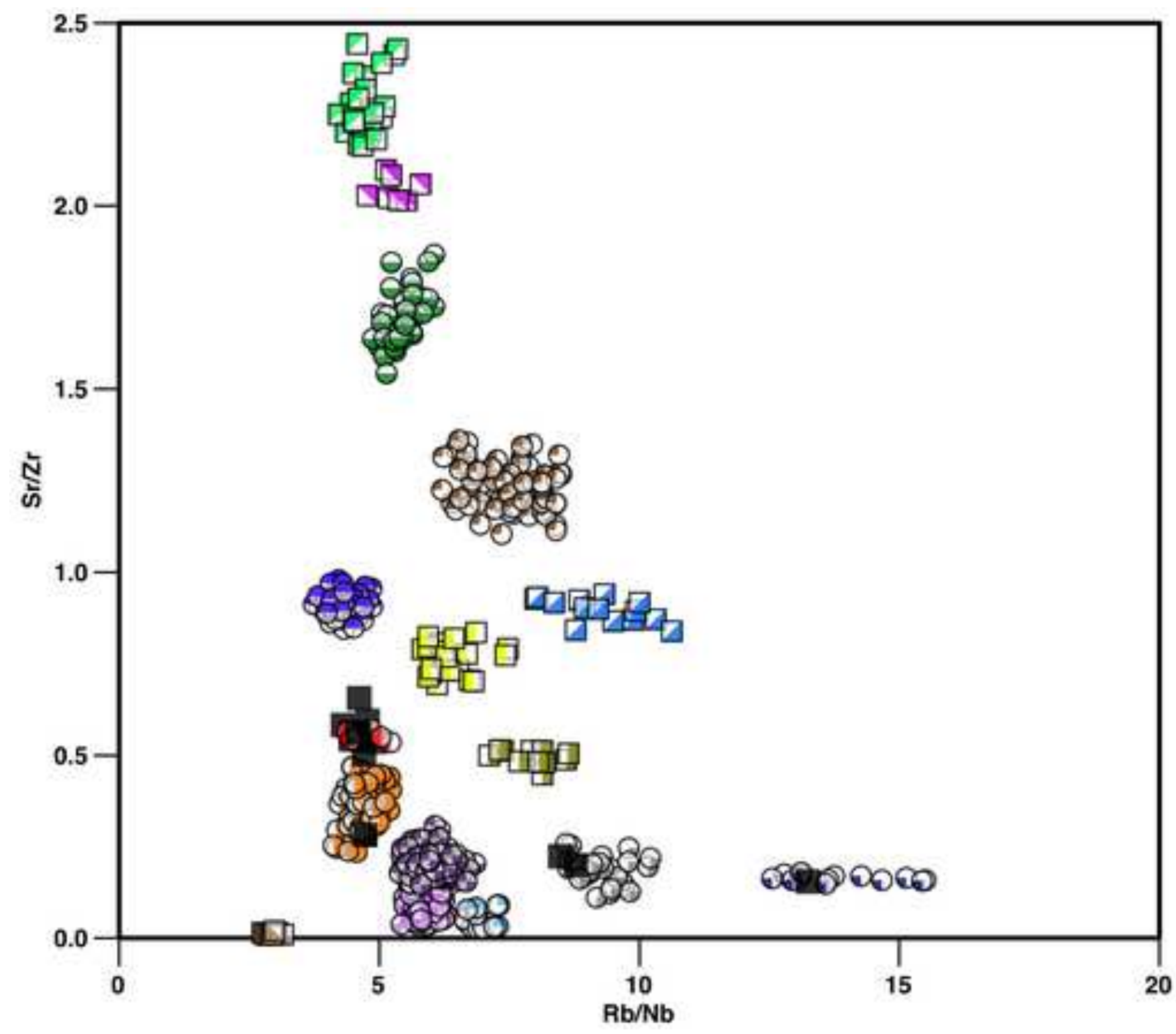

Domuztepe artifacts

O Pokr Arteni 1

(1) Pokr Arteni 2

○ East Göllü Dağ

- Bingöl B

$\odot$ Gutansar

$\bigcirc$ Hatis

$\checkmark$ Kamakar

$\square$ Kars-Digor 1

$\square$ Kars-Digor 2

O Khorapor

$\square$ Muş

Nenezi Dağ

O Satanakar

(1) Sevkar

$\square$ Ttvakar

O Chikiani/Paravani 

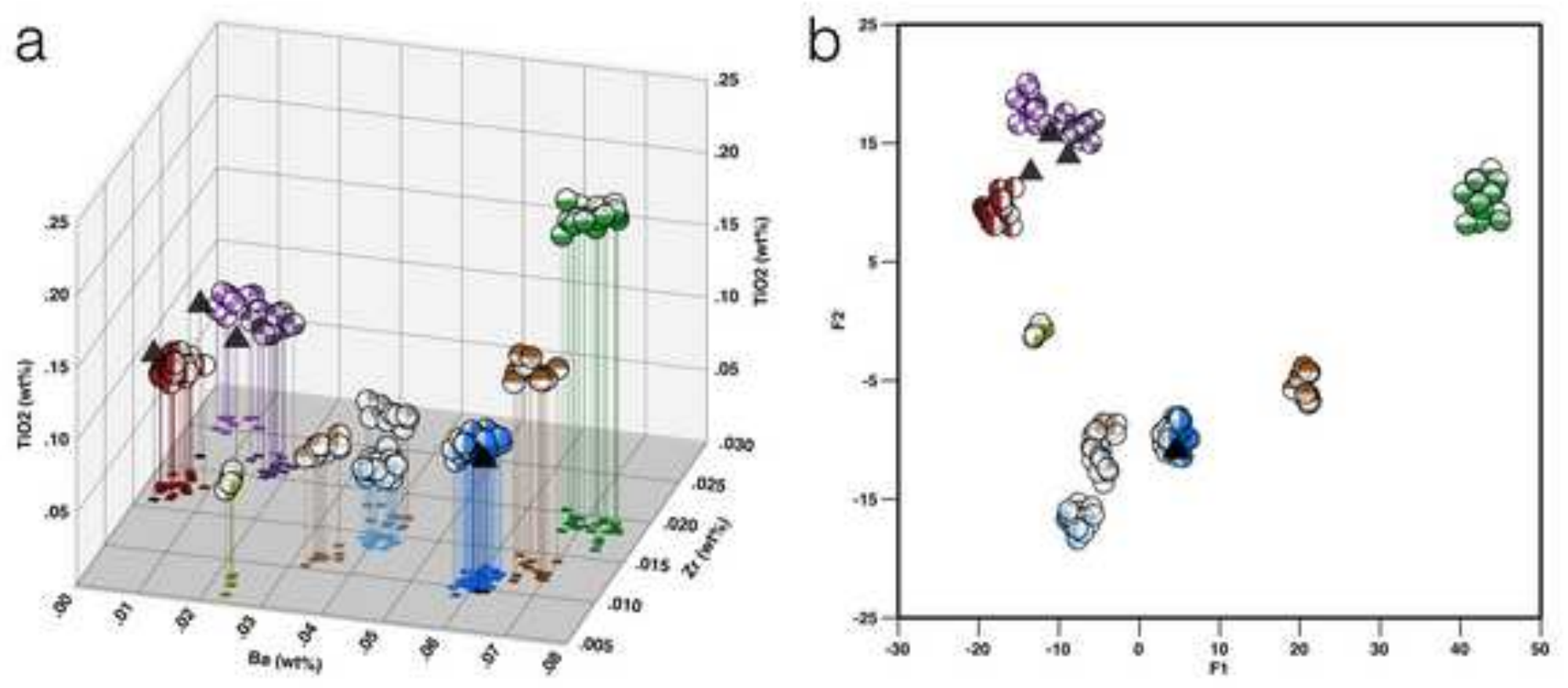
A Domuztepe artifacts
- Sankams
(1) Pasinler
(1) Kars-Avpecaly 1
Q Kars-Arpaçay 2
Kars-Digor 1
() Kars-Digor 2
Q Kars-Akbaba Dặ
O Erzunum
O Erzincan-Degirimen Tepe
O Erincan-Agli Tepe




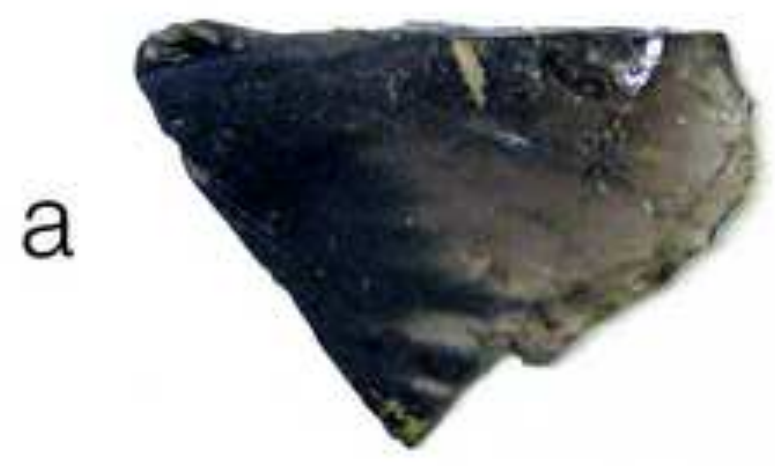

2.
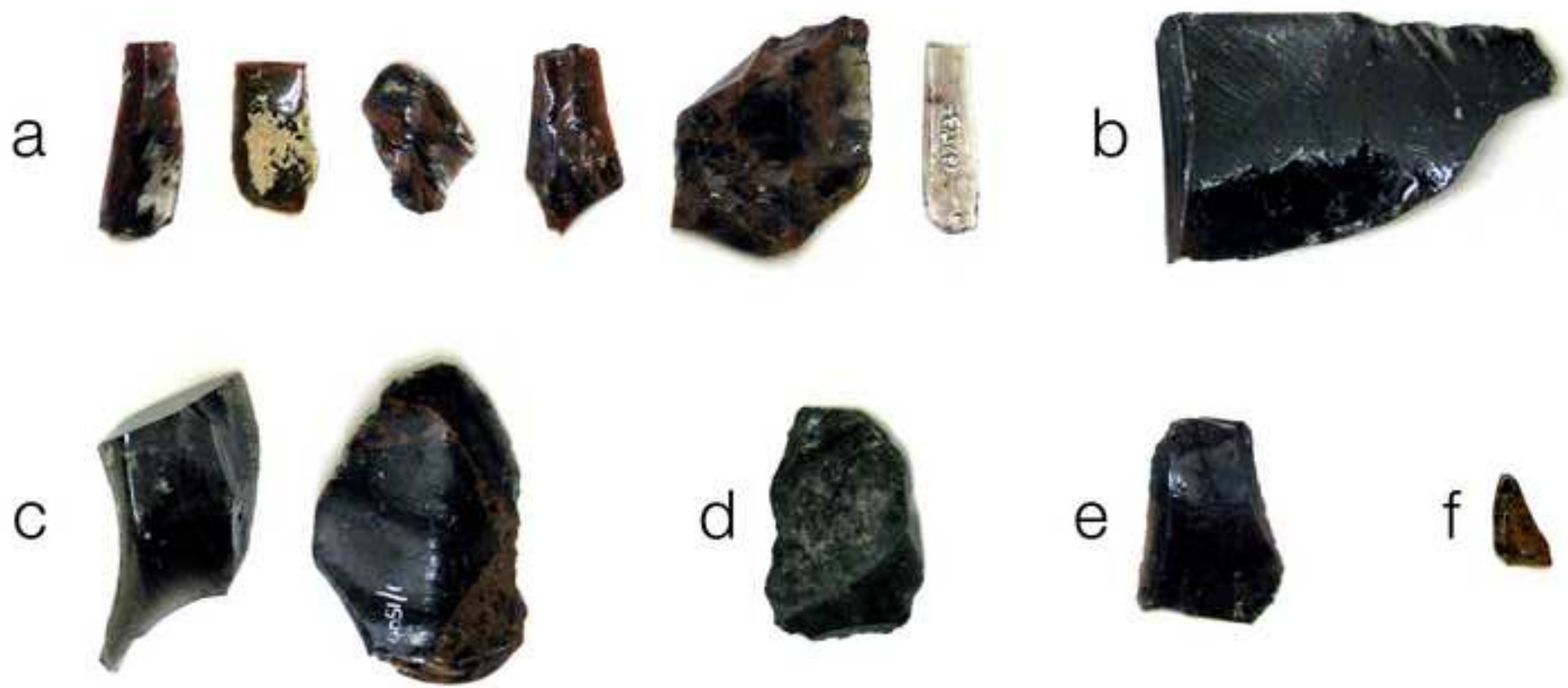

$\stackrel{0}{0-\infty \mathrm{cm} \quad 2}$ 